\title{
Macrophage-Derived Vascular Endothelial Growth Factor-A Is Integral to Neuromuscular Junction Reinnervation after Nerve Injury
}

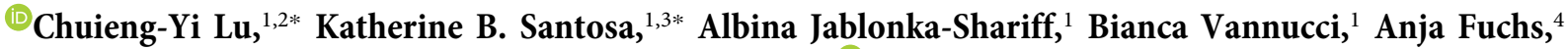 \\ Isaiah Turnbull, ${ }^{4}$ Deng Pan, ${ }^{1}$ Matthew D. Wood, ${ }^{1}$ and ${ }^{\mathbb{D}}$ Alison K. Snyder-Warwick ${ }^{1}$ \\ ${ }^{1}$ Division of Plastic Surgery, Department of Surgery, Washington University School of Medicine, St. Louis, Missouri 63110-1093, ${ }^{2}$ Division of \\ Reconstructive Microsurgery, Department of Plastic Surgery, Chang Gung Memorial Hospital, Chang Gung University, Taoyuan City, Guishan \\ District 33305, Taiwan, ${ }^{3}$ Section of Plastic and Reconstructive Surgery, Department of Surgery, University of Michigan, Ann Arbor, Michigan \\ 48109-4217, and ${ }^{4}$ Division of General Surgery, Department of Surgery, Washington University School of Medicine, St. Louis, Missouri 63110-1093
}

Functional recovery in the end target muscle is a determinant of outcome after peripheral nerve injury. The neuromuscular junction (NMJ) provides the interface between nerve and muscle and includes non-myelinating terminal Schwann cells (tSCs). After nerve injury, tSCs extend cytoplasmic processes between NMJs to guide axon growth and NMJ reinnervation. The mechanisms related to NMJ reinnervation are not known. We used multiple mouse models to investigate the mechanisms of NMJ reinnervation in both sexes, specifically whether macrophage-derived vascular endothelial growth factor-A (Vegf-A) is crucial to establishing NMJ reinnervation at the end target muscle. Both macrophage number and Vegf-A expression increased in end target muscles after nerve injury and repair. In mice with impaired recruitment of macrophages and monocytes (Ccr2-/mice), the absence of $\mathrm{CD} 68+$ cells (macrophages) in the muscle resulted in diminished muscle function. Using a Vegf-receptor 2 (VegfR2) inhibitor (cabozantinib; CBZ) via oral gavage in wild-type (WT) mice resulted in reduced tSC cytoplasmic process extension and decreased NMJ reinnervation compared with saline controls. Mice with Vegf-A conditionally knocked out in macrophages (Vegf-A $A^{f l f l}$; $L y s M^{C r e}$ mice) demonstrated a more prolonged detrimental effect on NMJ reinnervation and worse functional muscle recovery. Together, these results show that contributions of the immune system are integral for NMJ reinnervation and functional muscle recovery after nerve injury.

Key words: muscle recovery; nerve injury; neuromuscular junction; reinnervation; terminal Schwann cell; vascular endothelial growth factor

\section{Significance Statement}

This work demonstrates beneficial contributions of a macrophage-mediated response for neuromuscular junction (NMJ) reinnervation following nerve injury and repair. Macrophage recruitment occurred at the NMJ, distant from the nerve injury site, to support functional recovery at the muscle. We have shown hindered terminal Schwann cell (tSC) injury response and NMJ recovery with inhibition of: (1) macrophage recruitment after injury; (2) vascular endothelial growth factor receptor 2 (VegfR2) signaling; and (3) Vegf secretion from macrophages. We conclude that macrophage-derived Vegf is a key component of NMJ recovery after injury. Determining the mechanisms active at the end target muscle after motor nerve injury reveals new therapeutic targets that may translate to improve motor recovery following nerve injury.

Received July 8, 2020; revised Oct. 20, 2020; accepted Oct. 22, 2020.

Author contributions: C.-Y.L., K.B.S., A.J.-S., D.P., M.D.W., and A.K.S.-W. designed research; C.-Y.L., K.B.S., A.J.-S., B.V., A.F., D.P., and A.K.S.-W. performed research; A.F., I.T., and M.D.W. contributed unpublished reagents/analytic tools; C.-Y.L., K.B.S., A.J.-S., B.V., A.F., I.T., D.P., M.D.W., and A.K.S.-W. analyzed data; A.J.S., B.V., and A.K.S.-W. wrote the paper.

${ }^{*}$ C.-Y.L. and K.B.S. contributed equally to this work.

This work was supported by the National Institutes of Health National Institute of Neurological Disorders and Stroke Grants F32NS098561 (to K.B.S.), K08NS096232 (to A.K.S.-W.), and R01NS086773 (to D.P. and M.D.W.) and by the Plastic Surgery Foundation (A.K.S.-W.). We thank Dr. David Ornitz for kindly providing
Flk-1Cre; Rosa 26 tdTomatomice, Dr. Matthew Silva for the kind gift of Vegf-Afl/flmice, and Dr. Roberta Faccio and Dr. Benjamin Levi for generously supplying LysMCre mice. We thank Dr. Matthew MacEwan for use of Compound Muscle Action Potential testing equipment.

M.D.W. has been the recipient of sponsored research agreements from Checkpoint Surgical, Inc. and has consulted for Foundry Therapeutics, LLC and The Foundry, LLC. All other authors declare no competing financial interests.

Correspondence should be addressed to Alison K. Snyder-Warwick at snydera@wustl.edu.

https://doi.org/10.1523/JNEUROSCl.1736-20.2020

Copyright $\odot 2020$ the authors 

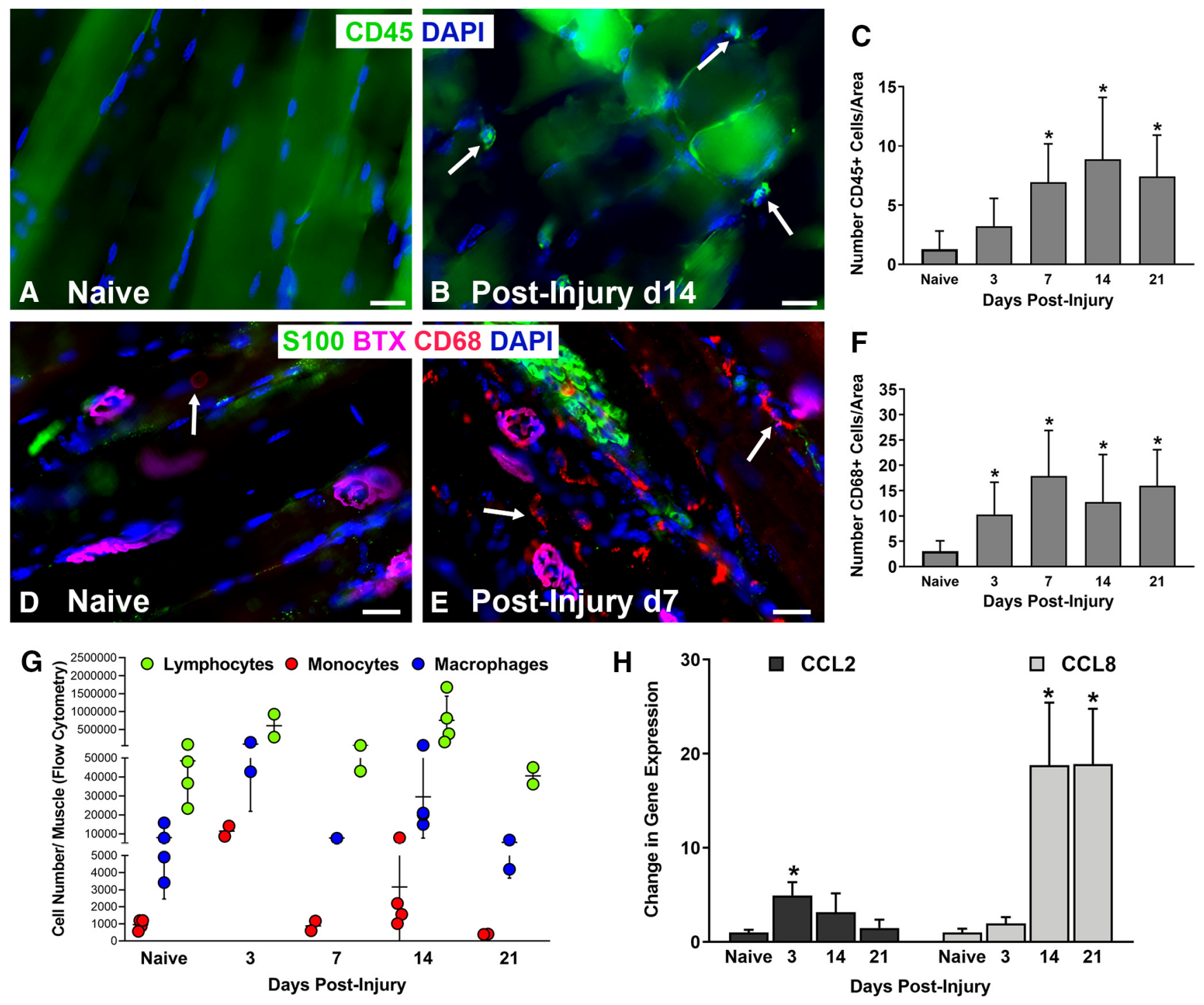

Figure 1. Increased leukocytes are present in the end target muscle following peripheral nerve injury in WT mice. A-C, Lymphocyte (CD45+, arrows) cell numbers significantly increased after nerve injury compared with naive, uninjured muscles and peaked at day 14. D-F, Macrophage (CD68+, arrows) cell numbers were significantly higher than in naive muscles at all time points from days 3 to 21 postinjury. $\boldsymbol{G}$, Flow cytometry revealed peak cell numbers in lymphocytes and macrophages at days 3 and 14 after nerve injury. $\boldsymbol{H}$, Gene expressions of the $C(\mathrm{Cr} 2$ ligands, chemokine-ligand-2 (CI2) and chemokine-ligand-8 (Cc/8), were significantly higher at days 3 and 14 , respectively, compared with naive muscles. $C(18$ remained elevated at day 21. $A, B, C D 45 A b=$ lymphocytes (green). D, E, CD68 Ab = macrophages (red), S100 Ab = glial cells (green), BTX $=\alpha$-bungarotoxin (endplates, purple), DAPI $=$ nuclear staining (blue). Scale bars: $20 \mu \mathrm{m}(\boldsymbol{A}, \boldsymbol{B})$ and $50 \mu \mathrm{m}(\boldsymbol{D}, \boldsymbol{E})$. Data: mean $\pm \mathrm{SD} ; N=3-4$ mice/time point; $* p<0.05$.

\section{Introduction}

Peripheral nerve injuries are common and devastating, disproportionately affecting young, healthy people (Grinsell and Keating, 2014). Although the peripheral nervous system is unique from the central nervous system in that it has the capacity to regenerate after injury, patient outcomes are often unsatisfactory (Novak et al., 2009; Ciaramitaro et al., 2010). Important factors predicting recovery from nerve injury include injury severity, duration, and location; patient age and health; and management approach (Boyd et al., 2011; Novak et al., 2011). Despite advancements in our understanding of the mechanisms contributing to nerve regeneration, further investigation is warranted to improve clinical outcomes. Comprehensive study of the entire system encompassing the neuronal cell body, axons, neuromuscular junction (NMJ), and end target muscle is necessary to understand the mechanisms contributing to repair and recovery.
Axonal regeneration across a nerve transection site has been shown to be largely driven by immune-mediated mechanisms (Cattin et al., 2015). Within hours of injury, calcium accumulation drives Wallerian degeneration resulting in axonal and myelin fragmentation distal to the injury site (Burnett and Zager, 2004; Faroni et al., 2015). Axonal debris leads to resident macrophage activation and circulating monocyte recruitment to the nerve injury site (Lech and Anders, 2013). Monocytes differentiate into macrophages after migration. Different macrophage phenotypes secrete factors integral to healing (Tomlinson et al., 2018), including vascular endothelial growth factor (VEGF), a key regulator of angiogenesis (Nissen et al., 1998; Stockmann et al., 2011; Shvartsman et al., 2014). Angiogenesis results in newlyformed blood vessels lined with endothelial cells (ECs) that guide myelinating Schwann cells (SCs), which then guide regenerating axons across a nerve injury site. Induced myeloid cell depletion has a net negative effect, compromising axonal regeneration and 
recovery of motor function, highlighting the importance of myeloid cells to the milieu supporting axonal regeneration (Barrette et al., 2008).

While these cellular mechanisms contributing to axonal regeneration in the nerve are well described, analogous mechanisms contributing to NMJ reinnervation have not been reported. Functional outcome after nerve injury is ultimately dependent on successful target muscle reinnervation at the NMJ. The NMJ represents the interface of nerve and muscle and consists of three main components: the nerve terminal, which releases acetylcholine (ACh) vesicles across the synaptic cleft, the postsynaptic motor endplates, or ACh receptors (AChRs), and one to three terminal SCs (tSCs; or perisynaptic SCs) that encompass the entire NMJ (Kang et al., 2003; Wilson and Deschenes, 2005; Smith et al., 2013; Santosa et al., 2018; Snyder-Warwick et al., 2018). These non-myelinating tSCs contribute to NMJ maintenance, signaling, and repair (Son and Thompson, 1995; Kang et al., 2014). After nerve injury, tSCs extend long processes to facilitate axon sprouting and guidance to the NMJ (Kang et al., 2014), but the contributions of tSCs to NMJ recovery following nerve injury are not fully understood. Specifically, interactions of tSCs with an immune response to facilitate NMJ recovery have not been reported. In this study, we demonstrate that an immune response occurs at the NMJ following nerve transection and repair. Specifically, we note an increase in macrophages and Vegf-A at the NMJ after nerve injury. We show that inhibition of: (1) macrophage recruitment; (2) Vegf-receptor 2 (VegfR2) signaling; and (3) macrophage-derived Vegf-A secretion all result in diminished tSC injury response and NMJ recovery.

\section{Materials and Methods}

Animals

All mice were housed in a central animal facility and were maintained preoperatively and postoperatively in strict accordance with the National Institutes of Health guidelines and according to protocols approved by the institutional animal research ethics committee (IACUC) at Washington University School of Medicine in St. Louis. For all experiments, adult (12- to 16-week-old) mice of both sexes were analyzed.

Wild-type (WT; pure C57BL/6 background) mice were bred in our laboratory. Chemokine receptor 2 (Ccr2) constitutive knock-out mice, Ccr2-1- (Willenborg et al., 2012), kindly provided by Gwendolyn Randolph (Washington University, St. Louis, MO), were used as a model lacking the ability to recruit monocytes and macrophages to injury sites and were bred in our lab. To generate a conditional knock-out of Vegf-A specifically in macrophages, Vegf-A $A^{f l f l}$; Lys $M^{C r e}$ mice were crossed to $V e g f-A^{f l / f l}$ mice (Gerber et al., 1999) and compared with Vegf- $A^{f l f l}$ controls. Vegf-A fl/fl mice were generously provided by Matthew Silva (Washington University, St. Louis) and LysM ${ }^{C r e}$ mice (Clausen et al., 1999), in which the $L y s M$ gene drives Cre expression in macrophages, were kindly provided by Roberta Faccio (Washington University, St. Louis) and Benjamin Levi (University of Michigan). To assess VegfR2 (also known as Flk-1), Flk-1 ${ }^{\text {Cre }}$; Rosa $26^{\text {tdTomato }}$ mice were generous provided by David Ornitz (Washington University, St. Louis; Motoike et al., 2003). Mutant mice were genotyped by the TAG Center of Transnetyx.
Surgical procedure for sciatic nerve injury and repair

Animals were anesthetized to an appropriate level via intraperitoneal ketamine and dexmedetomidine cocktail $(50 \mathrm{mg} / \mathrm{kg})$. Buprenorphine-SR $(1.0 \mathrm{mg} / \mathrm{kg})$ and saline were administered for postoperative pain control and hydration, respectively. The sciatic nerve from the right hindlimb was sharply transected and an immediate epineurial repair was performed with microsutures under a standard operating microscope as described previously (Vannucci et al., 2019). Animals were then placed on a heating pad, and anesthesia was reversed with Antisedan (0.5 mg/kg).

\section{Cabozantinib (CBZ) administration}

To determine the effect of lack of VegfR2 signaling, CBZ (XL184, MedChemExpress), a VegfR2 inhibitor (Yakes et al., 2011; Haider et al., 2015), was diluted in saline and administered via oral gavage beginning $6 \mathrm{~d}$ after nerve injury and repair as muscle Vegf-A expression begins to peak at $10 \mathrm{~d}$ postinjury and regenerating axons do not reach the NMJ until about that same time. WT mice were randomized to receive either $100 \mathrm{mg} / \mathrm{kg}$ of CBZ $(200 \mu \mathrm{l} / \mathrm{d})$ or saline control $(200 \mu \mathrm{l} / \mathrm{d})$ for $7 \mathrm{~d}$ (days $6-$ 13 following nerve injury and repair). Mice were then killed 14, 21, and $28 \mathrm{~d}$ after nerve injury ( $n=3 \mathrm{mice} /$ treatment/time point).

\section{Muscle harvest and immunocytochemistry}

At the designated time points (3-42 $\mathrm{d}$ postinjury), mice were anesthetized with intraperitoneal ketamine cocktail and then killed. The tibialis anterior (TA), extensor hallucis longus (EHL), and extensor digitorum longus (EDL) muscles were harvested from the injured and uninjured legs of the animal as described previously (Vannucci et al., 2019).

To evaluate macrophage markers (CD68), Vegf-A, and VegfR2 protein expression, muscles were fixed in $4 \%$ paraformaldehyde (PFA). Frozen sections $(25 \mu \mathrm{m}$ thick) were immunostained as described previously (Snyder-Warwick et al., 2018). The primary antibodies used include: mouse anti-VEGF-A (1:1200, Abcam catalog \#ab1316, RRID: AB_299738), mouse anti-VegfR2 (1:200, Cell Signaling Technology cata$\log$ \#2479, RRID:AB_2212507), rat anti-CD68 (1:500, Bio-Rad catalog \#MCA1957, RRID:AB_322219), and rat anti-CD45 (1:100, BD Biosciences catalog \#550539, RRID:AB_2174426). 

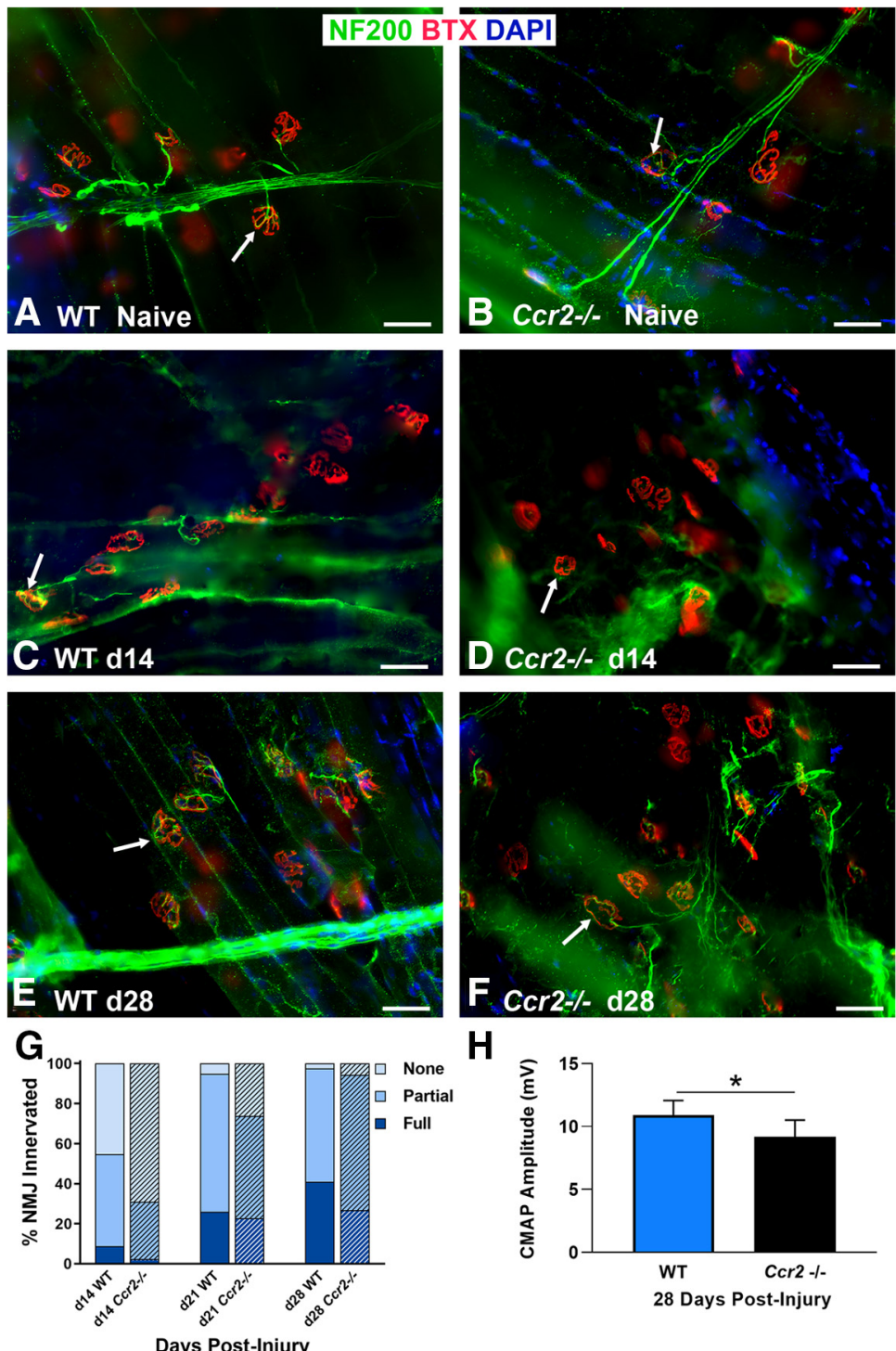

$\mathrm{H}$

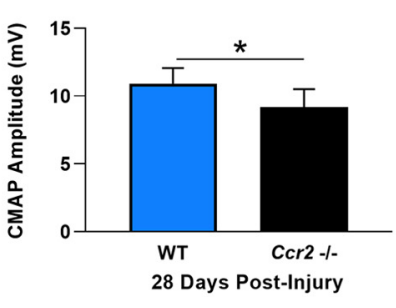

Figure 3. (Cr2-/ - mice exhibit decreased NMJ reinnervation and diminished muscle function following nerve injury and repair. $\boldsymbol{A}, \boldsymbol{B}$, WT and $(\mathrm{C} r 2-1-$ mice have normal NMJ morphology and innervation (arrows) in naive, uninjured muscles. $C, D, N M J$ reinnervation, represented by colocalization of neurofilament and motor endplate staining (arrows), was significantly decreased in $C(\mathrm{Cr} 2-/-$ mice compared with WT mice at $14 \mathrm{~d}$ after nerve injury and repair. A significant difference in innervation remained at $21 \mathrm{~d}$ (images not shown), but was mitigated by $28 \mathrm{~d}(\boldsymbol{E}, \boldsymbol{F}) . \mathbf{G}$, Bar graph summarizes the quantitative findings according to full, partial, or no NMJ innervation (none). $\boldsymbol{H}$, Evoked CMAPs of the TA muscle were significantly lower in C(r2-1- mice compared with WT mice at $28 \mathrm{~d}$ after nerve injury and repair, despite no difference in reinnervation at that time point. NF200 Ab $=$ axons (green), BTX $=\alpha$-bungarotoxin (endplates, red), DAPI = nuclear staining (blue). Scale bar: $50 \mu \mathrm{m}$. Data: mean \pm SD; $N=3-6$ mice/genotype/time point; $* p<0.05$.

To evaluate axonal reinnervation and tSC process extensions, EHL and EDL muscles fixed in 2\% PFA were mounted on slides as previously described (Jablonka-Shariff et al., 2019; Vannucci et al., 2019). Whole mounted muscles were stained with rabbit anti-NF200 (1:400; SigmaAldrich catalog \#N4142, RRID:AB_477272) or rabbit anti-S100 (1:10; Agilent catalog \#Z0311, RRID:AB_10013383) overnight at $4^{\circ} \mathrm{C}$. Both frozen sections and the whole mounts were incubated in secondary antibodies Alexa Fluor $488 \mathrm{~nm}$ or Alexa Fluor $594 \mathrm{~nm}$ (1:1000; Life Technologies). Tissues were further incubated with $\alpha$-bungarotoxin ( $\alpha$ BTX) Alexa Fluor 555 ( $\alpha$ BTX, 1:1000, Thermo Fisher Scientific cata$\log$ \#B35451, RRID:AB_2617152) or Alexa Fluor $647 \alpha$ BTX (1:1000). $\alpha \mathrm{BTX}$ binds specifically to AChRs in the postsynaptic membrane. Muscles were mounted on glass slides using Vectashield mounting medium with DAPI (Vector Laboratories catalog \#H-1200, RRID:AB_ 2336790).

\section{Morphometric evaluation}

All muscles were imaged under $20 \times$ magnification with an Axio Imager M2 fluorescent microscope (Zeiss). Images with a total area of $445.54 \times 333.66 \mu \mathrm{m}^{2}$ were analyzed using $\mathrm{NIH}$ ImageJ (https://imagej.nih.gov/ij/), and figures were prepared using Adobe Photoshop CC 2018 and Adobe Illustrator CC 2018 system (Adobe Systems). For quantitative analyses, muscle sections from at least three animals per group were processed, and at least five random sections, totaling $>100$ NMJs were analyzed per muscle.

$\alpha$ BTX was used to stain AChRs, S100 antibody was used to label all SCs (myelinating and non-myelinating), and NF200 antibody labeled neurofilament/axons. CD45 and CD68 were used to mark leukocytes and macrophages, respectively. The number of CD45+ and CD68+ cells were counted per field of view. Vegf-A protein expression was calculated as the percent of total area of the image analyzed. ImageJ macro was used to quantify Vegf-A expression. The percentage of the area in a standard field that was positive for Vegf-A was measured by the software. Images used for measurements were collected with similar microscopic settings for experimental and control groups. For endplate reinnervation and tSC process extensions, only the most superficial muscle layers were evaluated as previously described (Vannucci et al., 2019). NMJ reinnervation was defined as the colocalization of the nerve terminal stained with NF200 and AChRs stained with $\alpha$ BTX. NMJs were considered fully reinnervated if endplates were $\geq 75 \%$ covered with NF200 staining. Partial NMJ reinnervation was defined as colocalization of BTX and NF200 staining, but with $<75 \%$ coverage. No reinnervation, or denervation was defined as no NF200 staining present over BTX. Presence of $\mathrm{tSC}$ processes was defined as extension of the tSC cytoplasm branching outside the boundaries of the original motor end plates. The percentage of NMJs with tSC processes was evaluated after staining with S100. All evaluations were performed in a blinded fashion by three independent investigators.

\section{Functional muscle recovery assessments}

Functional TA muscle recovery was assessed at 14,21 , and $28 \mathrm{~d}$ after nerve injury and repair, before tissue harvest, using compound muscle action potentials (CMAPs) using FASt System, Red Rock Laboratories (Bogdanik et al., 2015; Vannucci et al., 2019). After anesthesia was induced, the sciatic nerve was exposed, and the previous nerve repair site was identified. The stimulating electrode was placed under the sciatic nerve at a location $10 \mathrm{~mm}$ proximal to the injury site. Two receiving electrodes were placed transcutaneously into the TA muscle belly, and the ground electrode was attached to a different part of body. After stimulation at $50 \mathrm{~Hz}$ CMAPs amplitudes were recorded. For comparison, CMAPs were also measured at the contralateral uninjured side. The CMAPs with the maximal peak-to-peak peak amplitudes (in $\mathrm{mV}$ ) were calculated for every mouse $(n=2$ or more mice per group per time point).

\section{Tissue processing for flow cytometry}

To analyze the immune cell composition within muscle at days $3,7,14$, and 21 after nerve injury, muscles from the affected hindlimb were 
collected from WT and Ccr2 $2^{-/-}$mice for collagenase digestion and leukocyte isolation using modifications of published procedures (Kuswanto et al., 2016; Pan et al., 2019). Muscles used for analysis included the majority of muscles innervated by sciatic nerve (TA, peroneus tertius, PL, PB, gastrocnemius, plantaris, soleus, tibialis posterior, FHL, FDL, and popliteus). For each flow cytometric sample, muscles from two hind limbs, i.e., affected muscles from two mice, were pooled. Muscles were minced, followed by digestion with $1 \mathrm{mg} / \mathrm{ml} \mathrm{Collagenase} \mathrm{II} \mathrm{and} 10 \mu \mathrm{g} / \mathrm{ml}$ DNase I (both from Sigma Aldrich) in RPMI 1640 media containing $2 \%$ fetal calf serum, for $45 \mathrm{~min}$ at $37^{\circ} \mathrm{C}$. Remaining tissue pieces were then dissociated through a $100-\mu \mathrm{m}$ cell strainer, and the resulting cell suspension was centrifuged at $500 \times g$. Immune cells were then enriched by Percoll gradient centrifugation, for which cells were resuspended in 40\% Percoll, overlayed over 70\% Percoll (GE Healthcare), and centrifuged for $20 \mathrm{~min}$ at 850 $\times g$ at $4^{\circ} \mathrm{C}$ without brake. The interphase was then washed with HBSS containing $10 \%$ calf serum, filtered through $70 \mu \mathrm{m}$, and resuspended in FACS buffer (PBS with $2 \%$ calf serum and $0.01 \% \mathrm{NaN}_{3}$ ). Nucleated cell counts and cell viability were determined by diluting cell suspensions with a mixture of acridine orange and propidium iodide and analyzing on a K2 Cellometer (Nexcelom).

Flow cytometry was performed using standard procedures (Fuchs et al., 2019). In short, enriched immune cells were incubated with TruStain FcX (anti-mouse CD16/32, Biolegend) to block Fc receptors for $10 \mathrm{~min}$ on ice, before staining with fluorochrome-conjugated antibodies. Antibodies used were purchased from BD Bioscience: CD45-BV510 (clone 30-F11), Siglec F-PE/CF594 (E50-2440), CD64-PE (X54-5/ 7.1.1); from Biolegend: CD11b-PerCP-Cy5.5 (M1/70), Ly6C-BV421 (HK1.4), Ly6G-Alexa Fluor 700 (1A8), and from R\&D Systems: MerTK-biotin (polyclonal). MerTK-biotin was detected with $\mathrm{PE} / \mathrm{Cy} 7$-conjugated streptavidin (BD Biosciences). Dead cells were excluded by staining with fixable live/ dead dye (Zombie NIR, Biolegend). Samples were acquired on an LSR Fortessa equipped with four lasers $(488,405,640$, and $552 \mathrm{~nm})$ using the Diva software (all from BD Biosciences), and data were analyzed with FlowJo 10 (Treestar Inc.). Macrophages were identified as CD $45^{+}$

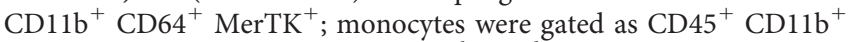
Ly6C $^{+}$Ly6G $^{-}$CD64 $^{-}$Siglec F $F^{-}$SSC ${ }^{\text {low-med }}$. Cell concentrations in stained samples were determined by adding counting beads to the samples immediately before flow cytometric acquisition (123count eBeads, eBioscience). Cell concentrations in samples were calculated per manufacturer's directions and were used to determine the cell counts in muscle from two hind limbs.

\section{$R N A$ extraction and quantitative $P C R$}

TA muscles were dissected and immediately placed in RNALater solution (Thermo Fisher Scientific), homogenized in TRIzol (Invitrogen), and stored at $-80^{\circ} \mathrm{C}$. Total extracted RNA was treated with RNase-free DNase (QIAGEN). The RNA pellet was further purified using RNeasy MinElute Cleanup kit (QIAGEN) according to the manufacturer's protocols and quantified with a NanoDrop ND-1000 spectrophotometer. Sample quality was evaluated with the $260 \mathrm{~nm} / 280 \mathrm{~nm}$ ratio. Complementary DNA was synthesized from total RNA $(100 \mu \mathrm{g})$ using High-Capacity cDNA Transverse Transcription kit (Applied Biosystems). Samples without reverse transcriptase (RT) enzyme, to control for genomic DNA contamination, were also included. RNA was extracted from at least 2 animals per group in the different models of the study.

Quantitative real-time PCR (qRT-PCR) was performed using TaqMan Fast Universal PCR Master mix and specific TaqMan PCR primers-probes combination were purchased from Applied Biosystems. Vegf-A (Mm00437306_m1) and Gapdh (Mm99999915_g1) Taq-Man Gene Expression Assays were used. All qPCR studies were performed on a Step One Plus instrument (Applied Biosystems), and results were analyzed using Microsoft Excel and $\Delta \Delta \mathrm{Ct}$ method (Livak and Schmittgen, 2001). Relative expression levels were calculated for the Vegf- $A$ gene by normalizing first to Gapdh level and then to the expression in sham uninjured muscle for each mouse genotype. Relative gene expression for muscle on the injured side is shown as fold change compared with the uninjured side. Samples were run in triplicate, and "non-template controls" with water and no RT enzyme were conducted as negative controls.

\section{Statistical analysis}

Continuous variables were reported as mean $\pm \mathrm{SD}$, while categorical variables were reported in percentages. Quantification of reinnervation and $\mathrm{tSC}$ process extension were performed in a blinded fashion with three independent evaluators, with three mice used per experimental group in every time point. Two-tailed, unpaired Student's $t$ tests were used to assess statistical differences between continuous variable datasets, while $\chi^{2}$ tests were used for categorical variables. Statistical significance was set at $p<0.05$. Statistical analyses were performed using GraphPad Prism 8 (GraphPad Software). 

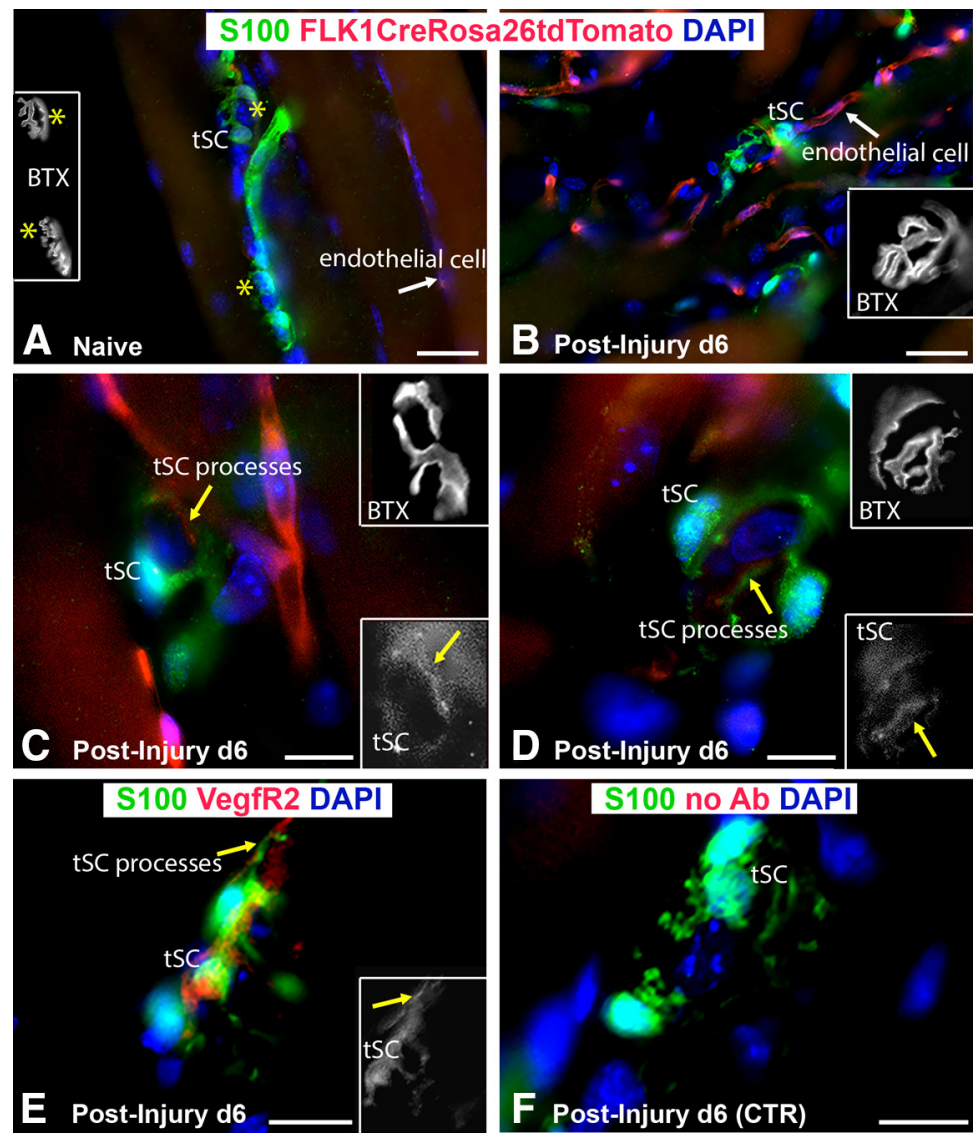

Figure 5. VegfR2 is expressed in tSC cytoplasm and processes connecting cell bodies after nerve injury. In order to determine VegfR2 localization, we used Flk-1 ${ }^{\text {(ree }}$; Rosa2 $6^{\text {tdTomato }}$ mice, where Rosa2 $6^{\text {TdTomato }}$ staining (red) is present at locations of VegfR2 (Flk-1) expression. $\boldsymbol{A}$, In naive muscles without previous nerve injury, VegfR2 was located on ECs (white arrows) but not in $\mathrm{tSCS}$ or around NMJs. B, At day 6 after nerve injury and repair, the NMJ with $\mathrm{tSCS}$ was surrounded by VegfR2expressing ECs (white arrow). C, D, At higher magnifications, VegfR2 localized within $\mathrm{SC} C$ cell bodies and cytoplasmic processes (yellow arrows) in addition to ECs. The single channel insets, pseudocolored in gray, highlight the positive staining of VegfR2 within the tSCs and tSC processes (yellow arrows). E, F, Colocalization of S100 staining (glia) with anti-Flk1 is seen at $\mathrm{tSCs}$ at $6 \mathrm{~d}$ postinjury. The inset $(\boldsymbol{E})$ represents a single red channel pseudocolored in gray showing the positive staining of VegfR2 in tSCs. Immunostaining for BTX (endplates, yellow stars) in panels $\boldsymbol{A}-\boldsymbol{D}$ are shown as insets pseudocolored in gray. These single-channel images represent BTX staining of the area shown in color. Flk-1 = VegfR2 (red), S100 Ab = glial cells (green), DAPI = nuclear staining (blue). $N=3$ mice/time point. Scale bars: $50 \mu \mathrm{m}(\boldsymbol{A}, \boldsymbol{B})$ and $20 \mu \mathrm{m}(\boldsymbol{C}, \boldsymbol{D})$.

\section{Results}

An immune response occurs at the NMJ in the end target muscle following nerve injury

After sciatic nerve transection and repair, increased leukocytes $(\mathrm{CD} 45+)$ and macrophages $(\mathrm{CD} 68+)$ were found in the EDL muscles from WT mice within the first two weeks after nerve injury and repair (Fig. 1A-G). Both leukocyte and macrophage (defined as CD45, CD11b, CD64, and MerTK positivity) cell numbers peaked within the first $14 \mathrm{~d}$ after nerve injury and repair via whole muscle flow cytometry (Fig. $1 G$ ), although significant differences were noted only at day 3: macrophages day 3 versus naive, $p<0.00502$; monocytes day 3 versus naive, $p<$ 0.0035 ; lymphocytes day 3 versus naive, $p<0.0466$. Quantitative analysis of immunostaining showed persistently elevated CD45+ and CD68 + cell numbers near the NMJ from days 3 to 21 after nerve injury and repair. Increased mRNA expression of the $\mathrm{Ccr} 2$ receptor ligands, chemokine-ligand-2 ( $\mathrm{Ccl} 2$; at $3 \mathrm{~d}$ after nerve injury) and chemokine-ligand-8 (Ccls; at $14 \mathrm{~d}$ after nerve injury), were significantly higher than naive muscles ( $\mathrm{Ccl} 2$ vs naive at $3 \mathrm{~d}: p<0.0304 ; C c l 8$ vs naive at $14 \mathrm{~d}: p=0.0004,21 \mathrm{~d}$ : $p=0.0009$; Fig. $1 H)$. The peaks in cytokine expression levels at 3 and $14 \mathrm{~d}$ postinjury correlate with peaks in monocyte and macrophage numbers within those same time points.

\section{The Ccr2-/- mouse exhibits decreased $\mathrm{NMJ}$ reinnervation and diminished muscle function following nerve injury and repair}

Given the robust immune response within the muscle of the WT mice following nerve injury, we further assessed the role of macrophages at the NMJ following nerve injury in the Ccr2-/- mouse, which lacks a major mechanism of monocyte and macrophage recruitment. Macrophage numbers did not differ at baseline between WT and Ccr2-/- mice (Fig. 2). Ccr2-/- mice were confirmed to have significantly $(p<0.000001)$ diminished macrophage recruitment to the NMJ after injury, however (Fig. 2). Ccr2-/- mice demonstrated overall normal NMJ morphology in naive muscle compared with WT mice (Fig. 3A, $B$ ), and performance on a walking grid test did not differ from uninjured WT mice (Wood MD, unpublished data). After nerve transection and repair, NMJ reinnervation was significantly decreased in Ccr2-/- mice compared with controls at 14 and $21 \mathrm{~d}$ postinjury (Fig. 3). Significantly less partial $(p<0.0052)$ and significantly more denervation (none, $p<$ 0.0043 ) were noted at $14 \mathrm{~d}$ postinjury in the Ccr2-/- mice compared with WT and $21 \mathrm{~d}$ after injury $(p<0.0276$ for partial, $p<0.0005$ for none). Quantitative differences in NMJ reinnervation mitigated by $28 \mathrm{~d}$ postinjury in all categories of innervation (Fig. 3G). In addition to morphologic reinnervation differences, Ccr2-/- mice exhibited diminished muscle function compared with WT mice at $28 \mathrm{~d}$ after nerve injury and repair. CMAP amplitudes were significantly lower $(p=$ $0.035)$ for Ccr $2-/-$ mice $(9.17 \pm 1.3 \mathrm{mV})$ compared with WT mice $(10.91 \pm 1.1 \mathrm{mV})$, despite equivalent reinnervation at this time point (Fig. 3H).

\section{Vegf-A expression increases in the end target muscle after nerve injury}

A critical role of macrophages after nerve injury is promoting formation of blood vessels that guide SCs to migrate across nerve gaps and mediate axonal regeneration (Cattin et al., 2015). Macrophages secrete Vegf-A, which promotes angiogenesis (Fantin et al., 2010) and may also recruit more macrophages from the blood stream (Cursiefen et al., 2004). Given the association of Vegf-A with macrophages, we hypothesized its presence in muscle is strongly correlated with NMJ reinnervation after nerve injury. Nearly undetectable Vegf-A protein levels were observed in muscles that were uninjured and following $1 \mathrm{~d}$ after nerve injury. By the third day postinjury, Vegf-A expression 

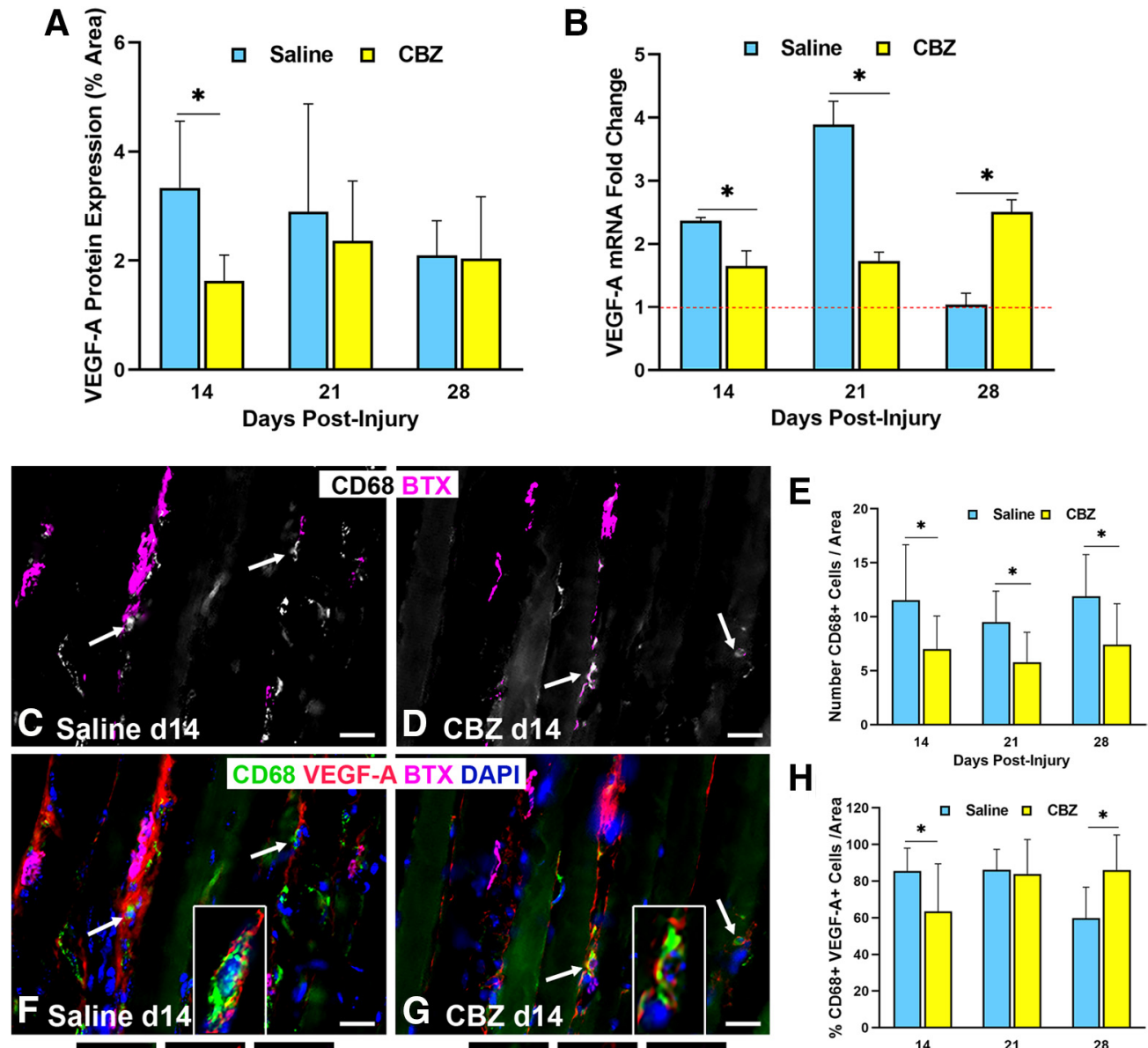

H
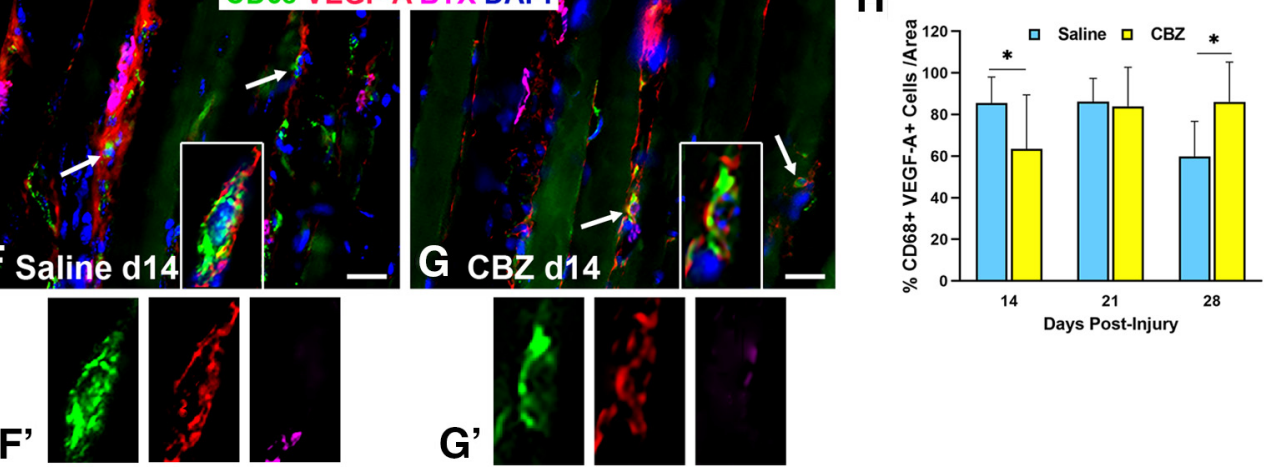

Figure 6. VegfR2 inhibition decreases Vegf-A expression and macrophage cell numbers after nerve injury. $A$, CBZ, a VegfR2 inhibitor, treatment (daily from days 6 to 13 following nerve injury) decreased Vegf-A protein expression at $14 \mathrm{~d}$ after nerve injury compared with saline-gavaged control mice. $\boldsymbol{B}$, In control mice, Vegf-A mRNA expression was elevated by $14 \mathrm{~d}$ postinjury, peaked at $21 \mathrm{~d}$, and returned to baseline by $28 \mathrm{~d}$. CBZ inhibited Vegf-A mRNA expression at days 14 and 21 postinjury, but the effect was not sustained by day 28. $\mathbf{C}-\boldsymbol{E}$, CBZ resulted in significantly decreased macrophage numbers at all time points. Arrows point to CD68+ cells (pseudocolored in gray in $\boldsymbol{C}, \boldsymbol{D}$ ). $\alpha$-Bungarotoxin staining of (BTX purple) demonstrates relationship of macrophages near NMJs. $\boldsymbol{F}-\boldsymbol{H}$, The percent of macrophages (green) colocalizing (arrows) with Vegf-A (red) was significantly less in the CBZ-treated group than saline-treated controls at day 14. The magnified images of single cells in $\boldsymbol{F}^{\prime}, \boldsymbol{G}^{\prime}$ highlight the colocalization of VegfA with a macrophages via isolated color channels. Vegf-A Ab (red), CD68 Ab = macrophages (green), BTX $=\alpha$-bungarotoxin (endplates, purple), DAPI $=$ nuclear staining (blue). Scale bar: $20 \mu \mathrm{m}$. Data: mean \pm SD; $N=3-5$ mice/treatment/time point; $* p<0.05$.

increased significantly $(p=0.0157)$ compared with uninjured muscles, and peaked at day 14 ( $p<0.001$; Fig. 4$)$.

\section{VegfR2 inhibition results in fewer Vegf-A-secreting macrophages at the NMJ}

Given the increased Vegf-A expression in the end target muscle following nerve injury, we investigated VegfR2 expression and signaling. VegfR2 localization was performed using the $F l k 1^{\mathrm{Cre}}$; TdTomato mouse, which exhibits Rosa staining at locations of VegfR2 (Sierra-Filardi et al., 2014). VegfR2 was noted within ECs of the blood vessels, tSCs, and nerve terminals at $6 \mathrm{~d}$ after nerve injury and repair (Fig. 5). We also investigated the impact of VegfR2 signaling inhibition with the VegfR2 inhibitor, CBZ. To determine the presence of a feedback loop for inhibition of VEGFR2 signaling, we evaluated VEGF-A levels, macrophages (CD68+ cells), and CD68+, Vegf-A+cells. $\mathrm{CBZ}$ administration to $\mathrm{WT}$ mice resulted in immediate, temporarily decreased Vegf-A protein expression in the muscles after nerve injury compared with saline-gavaged mice at $14 \mathrm{~d}(\mathrm{CBZ}=1.63$, saline $=3.33, p<0.001$; Fig. $6 \mathrm{~A})$. $V e g f-A$ mRNA expression levels were lower in the muscle of the nerve-injured hindlimb relative to the uninjured side in the CBZ group compared with controls at both $14 \mathrm{~d}(\mathrm{CBZ}=$ 1.65 , saline $=2.37, p<0.001)$ and $21 \mathrm{~d}(\mathrm{CBZ}=1.73$, saline $=$ $3.89, p<0.001$; Fig. $6 B$ ). Macrophage (CD68+ cells) numbers were significantly lower in the $\mathrm{CBZ}$ mice across all time points (Fig. 6C-E). Co-staining of Vegf-A with CD68 (Fig. $\left.6 F, G, F^{\prime}, G^{\prime}\right)$ revealed a significantly lower percentage of Vegf$\mathrm{A}+, \mathrm{CD} 68+$ cells in the CBZ group at $14 \mathrm{~d}(\mathrm{CBZ}=63.46 \%$, saline $=85.52 \%, p=0.004)$, indicating the presence of fewer Vegf-A-secreting macrophages (Fig. $6 F-H$ ). The number of cells co-staining with Vegf-A and CD68 were similar between CBZ-treated mice and controls at $21 \mathrm{~d}(p=0.67)$, reflecting the transient effect of the $\mathrm{CBZ}$ treatment. Vegf-A 

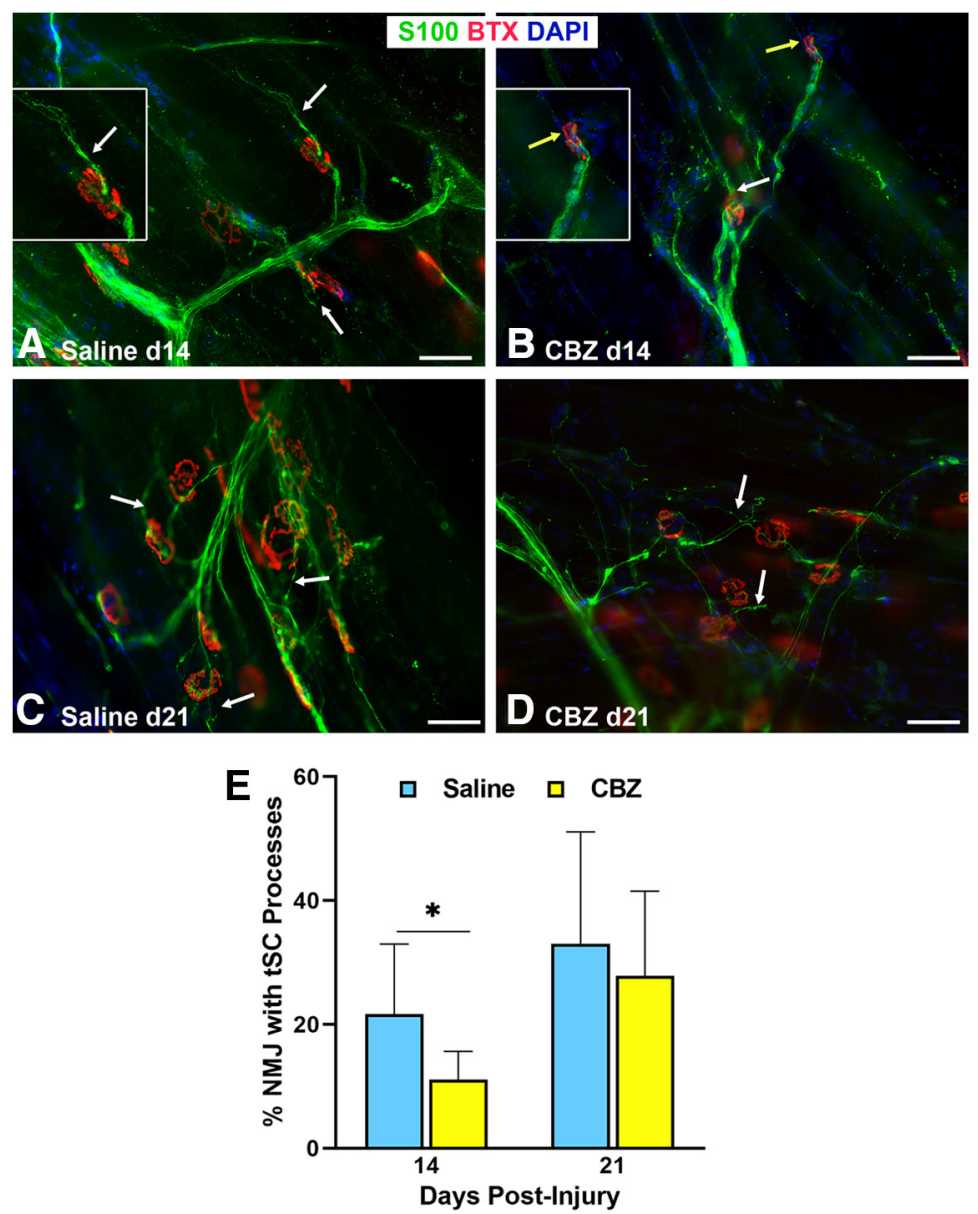

Figure 7. VegfR2/Negf-A inhibition reduces $\mathrm{SC}$ process extension beyond NMJ area after nerve injury. $A, B$, tSC cytoplasmic processes in the (BZ-treated mice (yellow arrows) were absent, short, or fragmented, and extended from fewer NMJs at day 14 compared with long $\mathrm{tSC}$ processes in saline-treated control mice (white arrows). The insets highlight long tSC processes (white arrow) in saline-treated mice $(\boldsymbol{A})$ and lack of processes (yellow arrow) in CBZ-treated mice $(\boldsymbol{B}) . \boldsymbol{C}, \boldsymbol{D}$, This effect did not persist on day 21 postinjury and repair ( $8 \mathrm{~d}$ after the last dose of $(B Z)$, as there was no difference between CBZ-treated mice and controls relative to percent NMJs with $\mathrm{SC}$ processes. $\boldsymbol{E}$, Quantitatively, the percentage of NMJs with $\mathrm{tSC}$ processes in CBZ-treated mice was half that of controls at $14 \mathrm{~d}$ and not significantly different from controls at $21 \mathrm{~d}$. $\mathrm{S} 100 \mathrm{Ab}=$ glial cells (green), $\mathrm{BTX}=\alpha$-bungarotoxin (endplates, red), DAPI = nuclear staining (blue). Scale bar: $50 \mu \mathrm{m}$. Data: mean $\pm S D ; N=3-5$ mice/treatment/time point; $* p<0.05$.

mRNA and the percentage of $\mathrm{CD} 68+$, Vegf-A + cells increased in CBZ treated mice at $28 \mathrm{~d}$, reflecting the transient nature of the inhibitor and a return to baseline values.

\section{VegfR2 (Flk-1) inhibition reduces tSC cytoplasmic process extension and NMJ reinnervation}

We hypothesized that Vegf-A supports NMJ reinnervation by guiding $\mathrm{tSC}$ process extension after nerve injury. $\mathrm{tSC}$ process extension was significantly $(p<0.05)$ decreased in the CBZ group $(11 \%)$ at $14 \mathrm{~d}$, as compared with the saline control group (22\%; Fig. 7). At $21 \mathrm{~d}$, the difference was no longer significant, which we suspect is related to the temporary effects of the drug. Morphologically, the tSC processes were shorter in length (Fig. $7 B$ ) in the $\mathrm{CBZ}$ group at $14 \mathrm{~d}$ after nerve injury but at $21 \mathrm{~d}$ the tSCs were still able to form processes (Fig. 7D). NMJ reinnervation was significantly decreased in the CBZ group compared with controls at $14 \mathrm{~d}$ postinjury when partial and full innervation were grouped together (CBZ 18.7\%, saline $34.1 \%, p=0.048$ ), but did not significantly differ in the three categories of full (CBZ $3.1 \%$, saline $10.2 \%, p<0.29$ ), partial (CBZ 15.6\%, saline $24.0 \%$, $p<0.28$ ), and none (CBZ 81.3\%, saline 65.9\%, $p<0.20$ ) as large standard deviations were noted in some groups. There were no differences in reinnervation between the $\mathrm{CBZ}$ and control groups at 21 or $28 \mathrm{~d}$ (Fig. 8), reflecting the temporary effects of CBZ. Electrophysiological testing by CMAP showed no significant differences between the two groups at all time points (Fig. $8 H$ ). The results show that Vegf-A in the muscle is intricately correlated with tSC function and NMJ reinnervation, but not muscle function.

\section{$V e g f-A^{f l f l} ; L y s M^{C r e}$ mice have a lower percentage of Vegf-A-secreting macrophages near the NMJ following nerve injury and repair}

VegfR2 inhibitor, CBZ, has limited bioavailability, short bioactivity, and non-specificity. To better assess the impact of Vegf-A on reinnervation, then, we used a transgenic model with conditional knock-out of Vegf-A specifically in macrophages using $V e g f-A^{f l / f l} ;$ Lys $M^{C r e}$ mice. Vegf-A $A^{f l / f l}$ mice were used as controls for comparison. Vegf-A protein expression in the muscles of $V e g f-A^{f l / f l}$; Lys $M^{\text {Cre }}$ mice was significantly decreased at $14 \mathrm{~d}(p<0.001)$ and $21 \mathrm{~d}$ $(p=0.011)$ after nerve injury (Fig. 9A). $V e g f-A$ gene expression via qPCR in TA muscles showed incremental increases from 7 to $28 \mathrm{~d}$ after nerve injury in control mice, whereas significantly $(p=0.011)$ lower levels of $V e g f-A$ mRNA expression were seen in the TA muscles of $V e g f-A^{f l / f}$; Lys $M^{\text {Cre }}$ mice at 7,14 , and $28 \mathrm{~d}$ postinjury compared with control mice. In Vegf-A fl/fi; $L y s M^{C r e}$ mice, muscle Vegf-A mRNA levels peaked at $21 \mathrm{~d}$ after nerve injury and then again decreased by $28 \mathrm{~d}$ (Fig. 9B). Unlike the CBZ model, CD68+ macrophage counts near the NMJ after nerve injury in Vegf-A $A^{f l / f}$; Lys $M^{\text {Cre }}$ mice were either higher (days 7 and $28, p<0.05$ ) or comparable (days 14 and 21) to control mice (Fig. $9 C-G$ ). Co-staining of Vegf-A with CD68 in the muscles (Fig. 9H) revealed a significantly lower percentage of CD68+ cells expressing Vegf-A in the Vegf-A flfl ; Lys $M^{\text {Cre }}$ mice at all time points, as expected in this model. Vegf expression seen in the Vegf- $A^{f l / f l}$; LysM ${ }^{C r e}$ mice is contributed by ECs within blood vessels and inefficiency of the conditional mutation, as a small number of macrophages continue to express Vegf-A.

\section{$V e g f-A^{f l f l} ; L y s M^{C r e}$ mice have fewer tSC processes,}

diminished NMJ reinnervation, and poor functional recovery following nerve injury and repair

Evaluation of tSC process extension showed significantly fewer processes in Vegf-A $A^{f l f l}$; Lys $M^{\text {Cre }}$ mice compared with controls at all time points up to $21 \mathrm{~d}$ after nerve repair (Fig. 10). By $28 \mathrm{~d}$, tSC process extensions were observed in the Vegf-A $A^{f l f f} ; L y s M^{C r e}$ mice (Fig. $10 H$ ), while the control mice showed less tSC communication between motor end plates, indicating potential withdrawal of the tSC processes after successful reinnervation (Fig. 10G). Full NMJ reinnervation was significantly less in the Vegf- $A^{f l / f l}$; 
Lys $M^{\text {Cre }}$ mice at $21 \mathrm{~d}$ (control 62.13\%, $V e g f-A^{f l f l} ; \quad$ LysM $\left.M^{C r e} 28.30 \%, p<0.0036\right)$. Denervation (none) was significantly higher in the the Vegf-A $A^{f l f l}$; Lys $M^{C r e}$ mice at $21 \mathrm{~d}$ compared with controls (control 19.2\%, Vegf-A flffl LysM $M^{\text {Cre }} 58.8 \%, p<$ 0.0272 ). By $28 \mathrm{~d}$ after nerve repair, when tSC process extension continued to increase in $V e g f-A^{f l f l}$; Lys $M^{C r e}$ mice, full NMJ reinnervation was nearly $80 \%$ in both groups (Fig. 11). Despite equivalence of morphologic reinnervation data at $28 \mathrm{~d}$, $V e g f-A^{f l f l} ; L y s M^{C r e}$ mice demonstrated significantly poorer CMAP performance at this time point compared with control mice $(p=0.0065)$, indicating a not only a morphologic difference, but also functional impact from macrophage-derived Vegf-A deletion in the setting of nerve injury and NMJ reinnervation.

\section{Discussion}

The immune response is important for axonal regeneration at the nerve transection site (Cattin et al., 2015). In this study, we show an immune response also occurs in muscle and is integral to NMJ reinnervation following nerve injury. We first showed an inflammatory response downstream from the injury, including monocyte and macrophage recruitment to the target muscle and increased $\mathrm{Ccl} 2$ and Ccl8 expression, responsible for attracting monocytes from bloodstream to target muscle. The Ccr2-1- mouse model (impaired macrophage recruitment) showed monocytes and macrophages are important for NMJ reinnervation and end target muscle function after nerve injury. Impaired macrophage recruitment resulted in delayed NMJ reinnervation and diminished muscle function, even after NMJ reinnervation, demonstrating innervation is not equivalent to synaptic function. We showed Vegf-A expression within muscle increased from $3 \mathrm{~d}$ after nerve injury and repair, suggesting neurons are not the source of Vegf-A. VegfA levels are not elevated in uninjured WT mice and increase before regenerating axons reach the NMJ. Disruption of Vegf-A signaling with VegfR2 inhibitor, CBZ, or using a transgenic mouse model lacking macrophage-secreted Vegf-A, resulted in fewer tSC cytoplasmic processes (which normally extend after denervating injuries), decreased NMJ reinnervation, and diminished muscle function. These findings are noteworthy as diminished or delayed NMJ reinnervation should result in increased tSC process extension. In summary, we have shown NMJ reinnervation hindrance with inhibition of the following: (1) macrophage recruitment; (2) VegfR2 signaling; and (3) Vegf-A secretion from macrophages. We conclude that macrophage-secreted Vegf-A is a key component of NMJ recovery after injury. treatment/time point.
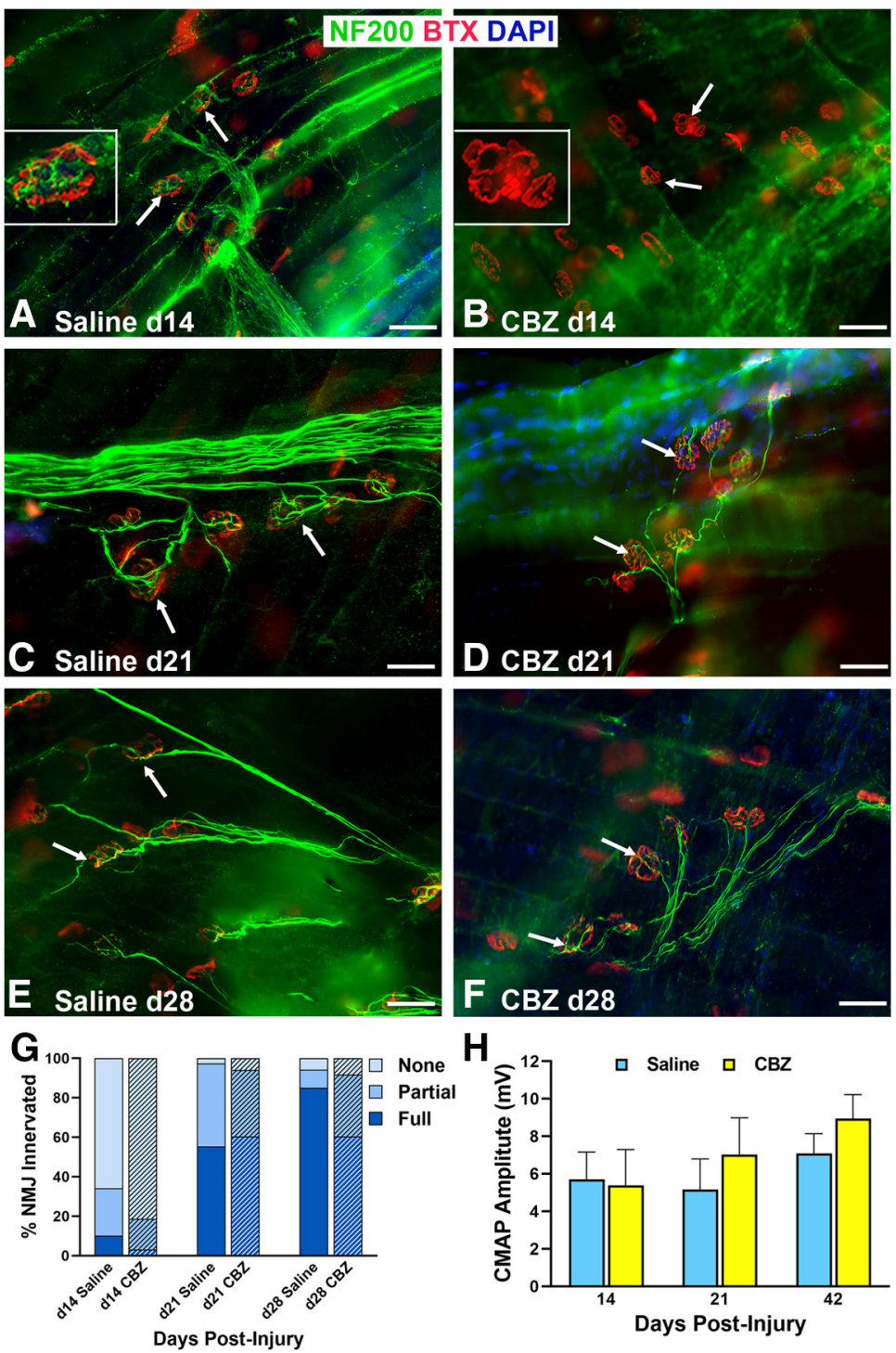

Figure 8. VegfR2/Vegf-A inhibition reduces NMJ reinnervation after nerve injury. $\boldsymbol{A}, \boldsymbol{B}$, NMJ reinnervation, defined as overlap of axonal staining (NF200 Ab, green) with $\alpha$-bungarotoxin (BTX, endplates, red) staining (arrows), was significantly less in (BZ-treated mice compared with controls at day 14, but not at days 21 (C, D) or $28(\boldsymbol{E}, \boldsymbol{F})$ after nerve injury and repair. The insets highlight innervated endplate $(\boldsymbol{A})$ and denervated endplate $(\boldsymbol{B})$ in saline-treated and CBZ-treated mice, respectively. $\boldsymbol{G}$, Quantification analyses showed both full and partial NMJ reinnervation in CBZ-treated mice were approximately half the values of controls at $14 \mathrm{~d}$ postinjury. The percentage of fully reinnervated NMJs did not change from 21 to $28 \mathrm{~d}$ postinjury in the CBZ group. $\boldsymbol{H}$, There were no differences in CMAP amplitudes between CBZ-treated mice and saline-treated controls at all time points postinjury. DAPI = nuclear staining (blue). Scale bar: $50 \mu \mathrm{m}$. Data: mean $\pm S D ; N=3-5$ mice/

VegfR2 (or Flk-1), the receptor responsible for initiating downstream Vegf-A pathways, is found in ECs, initiates angiogenesis, and increases vessel permeability (Olsson et al., 2006). In the nervous system, VegfR2 is expressed in neuronal cells (Krum and Rosenstein, 1998; Park et al., 2016), SCs (Sondell et al., 1999a,b), and ECs involved in posttraumatic or developmental angiogenesis (Krum and Rosenstein, 1998; Rosenstein et al., 1998). Interestingly, most studies focusing on VegfR2 effects have been conducted on CNS tissue or cells. In the PNS, exogenous Vegf-A has neurotrophic actions which can trigger neurite extension and promote axonal outgrowth in cultured ganglia cells (Sondell et al., 1999b). In an in vivo model, nerve allografts pretreated with Vegf-A showed enhanced SC growth and 

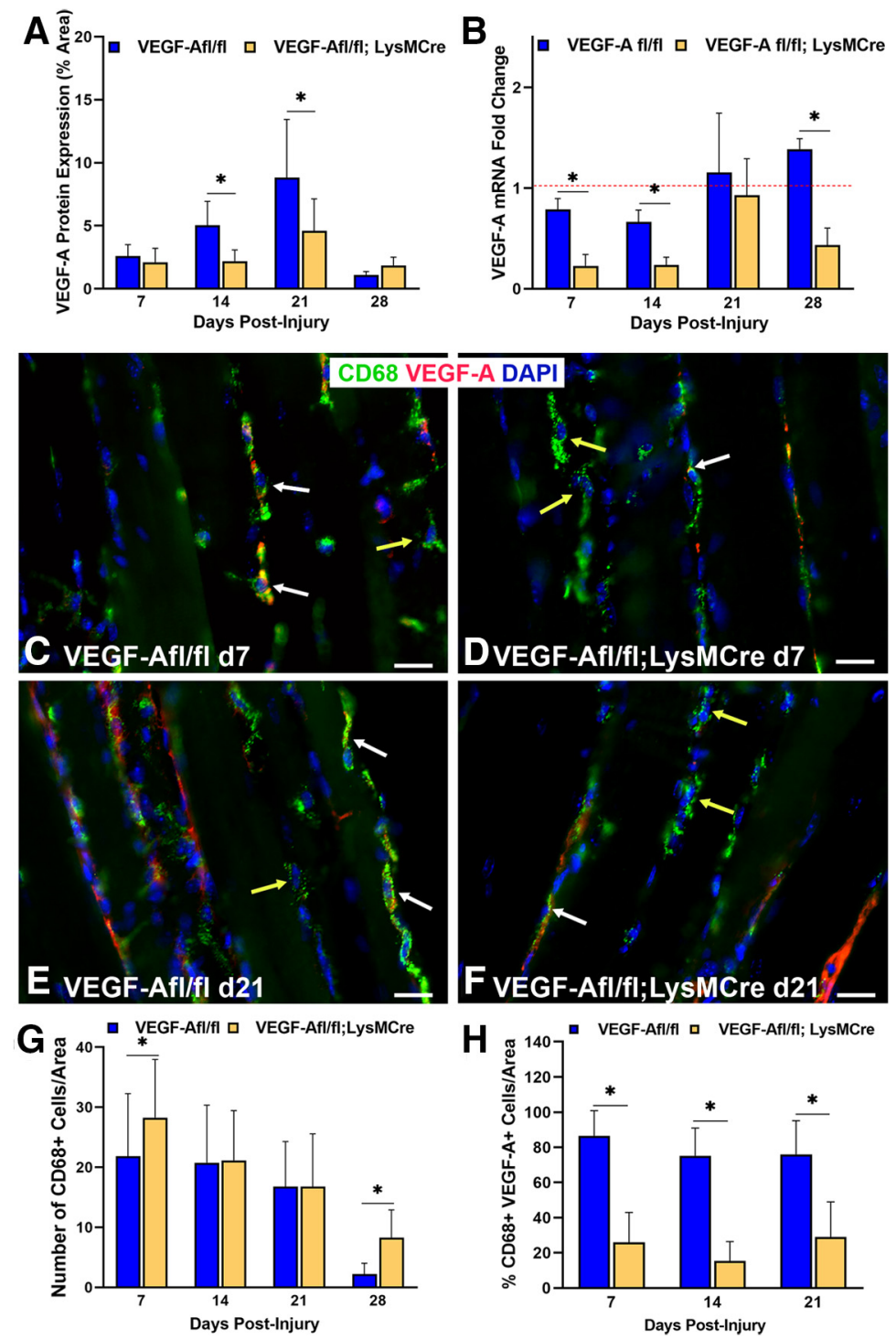

Figure 9. Vegf-A expression within macrophages is decreased in Vegf-Al/fif $L y s M^{(r e}$ mice. $A$, Vegf-A protein expression was significantly decreased in Vegf-A/f/fi $L_{\text {Ls }} M^{\text {(re }}$ mice at days 14 and 21 following nerve injury and repair. Vegf-A levels peaked in both conditional knock-out mice and controls $\left(\right.$ Vegf- $\left.A^{f / / f}\right)$ at $21 \mathrm{~d}$ postinjury. $B$, Vegf-A mRNA expression was significantly decreased in Vegf-A ${ }^{f / f} ;$; $L s M^{C r e}$ mice compared with the control mice. Vegf-A mRNA expression peaked at day 21 in the Vegf-A $A^{f / H}$; Lys $M^{\text {Cre }}$ mice before significantly decreasing again at $28 \mathrm{~d}$ after nerve injury. $\mathbf{C}-\boldsymbol{H}$, Macrophage (green) number was higher in the Vegf-Afl/f; Lys $M^{\text {Cre }}$ mice compared with controls at days 7 and 28 after nerve injury but did not differ between Vegf-Al/fif; $L y s M^{\text {(re }}$ mice and controls at days 14 and 21. Both groups had fewer macrophages present in the muscle at day 28. G, The percentage of CD68+ cells (green) colocalizing with Vegf-A (red, white arrows in $(-F)$, however, was significantly decreased in Vegf-Affff; $L y s M^{(\text {re }}$ mice compared with controls at all time points. Macrophages not colocalized with Vegf-A are indicated by yellow arrows. Vegf-A Ab (red), CD68 Ab = macrophages (green), DAPI = nuclear staining (blue). Scale bar: $20 \mu \mathrm{m}$. Data: mean \pm SD; $N=3$ mice/genotype/ time point; $* p<0.05$.

neovascularization, and VegfR2 was identified in SCs within nerve allograft (Sondell et al., 1999a). Raimondo et al. (2019) injected alginate hydrogels secreting Vegf-A and insulin-like growth factor 1 directly into the target muscle following nerve injury and showed improved functional reinnervation, citing an increased neurotransmitter or postsynaptic response. Similarly, exogenous alginate gel Vegf-A delivery to ischemic muscle after nerve crush demonstrated beneficial NMJ recovery effects: delayed Wallerian degeneration, AChR protection, and nerve growth factor-derived and glial-derived nerve growth factor-dependent angiogenesis (Shvartsman et al., 2014). Our study shows that Flk-1/VegfR2 exists in both myelinating SCs within nerve and non-myelinating tSCs at the NMJ (Fig. 5). These data suggest Vegf-A signaling induces SCs to extend cytoplasmic processes to guide the incoming regenerating axons at both the nerve injury site (Gomez-Sanchez et al., 2017) and the NMJ (Santosa et al., 2018). In the transgenic mouse, macrophage-derived Vegf-A is diminished at all time points when $\mathrm{tSC}$ processes are decreased compared with controls (Figs. 9, 10). Furthermore, increased Flk-1/ VegfR2 intensity in ECs around the NMJ combined with higher Vegf-A expression levels highlight the potential for increased vessel permeability, allowing additional immune cell recruitment. Given the trophic role Vegf-A plays in neurogenesis and angiogenesis in the developing or posttraumatic nervous system (Rosenstein et al., 2010; Shvartsman et al., 2014), our results strongly indicate that Vegf-A is integral to $\mathrm{tSC}$ morphologic changes during $\mathrm{NMJ}$ reinnervation. The relationship of $\mathrm{tSC}$ processes and angiogenesis requires additional investigation. Interestingly, we showed Vegf-A signaling inhibition via different mechanisms resulted in decreased tSC cytoplasmic process extension over a delayed time course; tSC process extension is necessary for NMJ reinnervation. tSC processes normally extend beginning $3 \mathrm{~d}$ after nerve transection and diminish as NMJ reinnervation occurs or over fourweeks (O'Malley et al., 1999). Since denervation would stimulate tSC process formation (Reynolds and Woolf, 1992; Son and Thompson, 1995; Rosenstein et al., 1998; Koirala et al., 2000; Kang et al., 2014), and we observed less tSC process extension, these data suggest Vegf-A signaling changes are directly linked to $\mathrm{tSC}$ process formation.

As tSC processes guide axons to the NMJ (Reynolds and Woolf, 1992; Kang et al., 2003, 2014), altered tSC function likely contributed to decreased NMJ reinnervation, resulting in diminished muscle function in the absence of Vegf-A signaling. Our data show tSCs respond to immune environment alterations and highlight the importance of tSC-macrophage (and macrophage-secreted Vegf-A) interactions and $\mathrm{tSC}$-nerve terminal interactions. tSCs are key NMJ regulators contributing to NMJ signaling (Jahromi et al., 1992; Reist and Smith, 1992; Corfas et al., 2004), maintenance (Reddy et al., 2003; Barik et al., 2016), and repair (Smith et al., 2013; Ko and Robitaille, 2015; Lee et al., 2016). tSCs aid NMJ reinnervation by expressing Ccl 2 to recruit circulating monocytes (Fischer et al., 2008). tSCs, then, may both initiate and interact with the cellular responses at the NMJ after injury. Myelinating SCs are a target of macrophage signaling; macrophages regulate SC differentiation and maturation following nerve injury (Stratton et al., 2018). At the NMJ, tSCs are similarly key interactors with macrophage-secreted Vegf-A.

The finding of an immune response downstream from the nerve injury site, within the end target muscle, is novel. While 
we conclude that $\mathrm{tSCs}$ interact with the immune response at the NMJ, the mechanisms triggering inflammation there require further elucidation. Our results contribute to literature regarding the importance of the inflammatory response distant from the nerve injury. After optic nerve injury, downstream inflammatory events, including increased CD68 + cells, have been described (Tonari et al., 2012). Furthermore, unilateral optic nerve injury leads to microglial inflammatory responses in both the ipsilateral and contralateral retinas (Sobrado-Calvo et al., 2007). Macrophages may impact $\mathrm{tSCs}$ at the NMJ in our sciatic nerve transection model similarly to microglial cells at the retina in an optic nerve injury model. The presence of inflammatory effects downstream from the injury site may have translational therapeutic implications. Elicitation of the NMJ injury response mechanisms are essential to our understanding of motor recovery following nerve injury and may have importance for other organ systems as well.

Our data support previous reports outlining benefits of inflammation for recovery in multiple injury types. Macrophages, for example, are important for cutaneous wound healing via promotion of inflammation and angiogenesis; alterations in macrophage phenotype influence chronic wound formation (Koh and DiPietro, 2011). Similarly, impaired monocyte recruitment from the bloodstream in Ccr2-deficient mice resulted in impaired cutaneous wound healing that corrected with WT monocyte and macrophage transfer (Boniakowski et al., 2018). The importance of macrophage-driven inflammation, including VEGF release, for recovery has also been established in models of liver injury (You et al., 2013), as well as muscle (Arnold et al., 2007; Shireman et al., 2007) and bone (Alexander et al., 2011; Schlundt et al., 2018) healing. In nerve, axonal regeneration across a transection injury follows the process of macrophage Vegf-A secretion, followed by angiogenesis, SC migration across ECs, and finally axonal regeneration along SC tubes (JablonkaShariff et al., 2019). Inflammation, although a commonly targeted pathophysiological process, can be beneficial.

The immune system's contributions to healing are complex and multi-phased. Neutrophils are the first $(24 \mathrm{~h})$ immune cells to respond after injury. Although they contribute to healing by phagocytosis of debris, they are not essential (Martin and Leibovich, 2005). Infiltrating monocytes are recruited to the injury site within $48-96$ h via receptors such $* p<0.05$
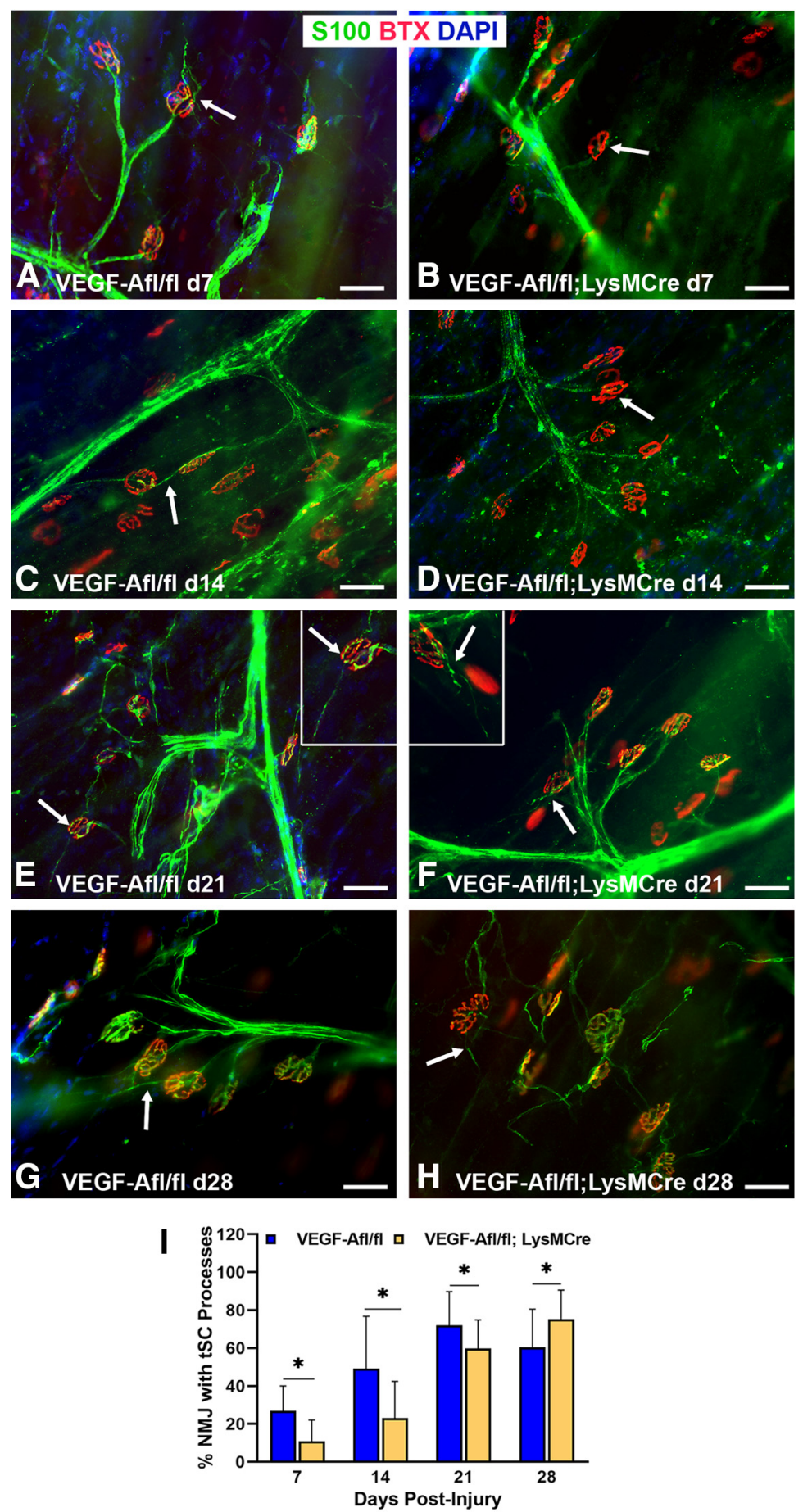

Figure 10. $\quad \mathrm{tSC}$ process extension is diminished after nerve injury in Vegf-A/fff; $L y s M^{(r e}$ mice. $A$, At day 7 after nerve injury, $\mathrm{tSCS}$ extended their processes (arrow) in control mice. In contrast, $\mathrm{TSC}$ process extension was absent (arrow) at the NMJs in Vegf-A $A^{f / f} ;$; Lys $M^{(r e}$ mice $(\boldsymbol{B})$. Significant differences in tSC process extension persisted at days $14(\boldsymbol{C}, \boldsymbol{D})$ and $21(\boldsymbol{E}, \boldsymbol{F})$ postinjury. The inset in panel $\boldsymbol{E}$ shows an NMJ with a long tSC process (arrow) in control mice. The inset in panel $\boldsymbol{F}$ shows two endplates in Vegf-Aflff; $L y s M^{\text {cre }}$ mice but only one (arrow) with a very short $t S C$ process. By day 28, however, thinner $t S C$ processes were present in the NMJs of Vegf- $A^{f f / f} ;$ L $L y s M^{C r e}$ mice $(\boldsymbol{H})$ than in controls $(\boldsymbol{G})$. $\boldsymbol{I}$, Significant differences in the percent of NMJs with tSC process extension was most evident from days 7 to 21 . S100 Ab = glial cells (green), BTX $=\alpha$-bungarotoxin (endplates, red), DAPI = nuclear staining (blue). Scale bar: $50 \mu \mathrm{m}$. Data: mean \pm SD; $N=3$ mice/genotype/time point;

as Ccr2, a promiscuous receptor that responds to a variety of signals, including Ccl2 and Ccl8 (Sondell et al., 1999a; Willenborg et al., 2012; Jablonka-Shariff et al., 2019). Once in tissue, recruited monocytes differentiate into inflammatory phenotype 

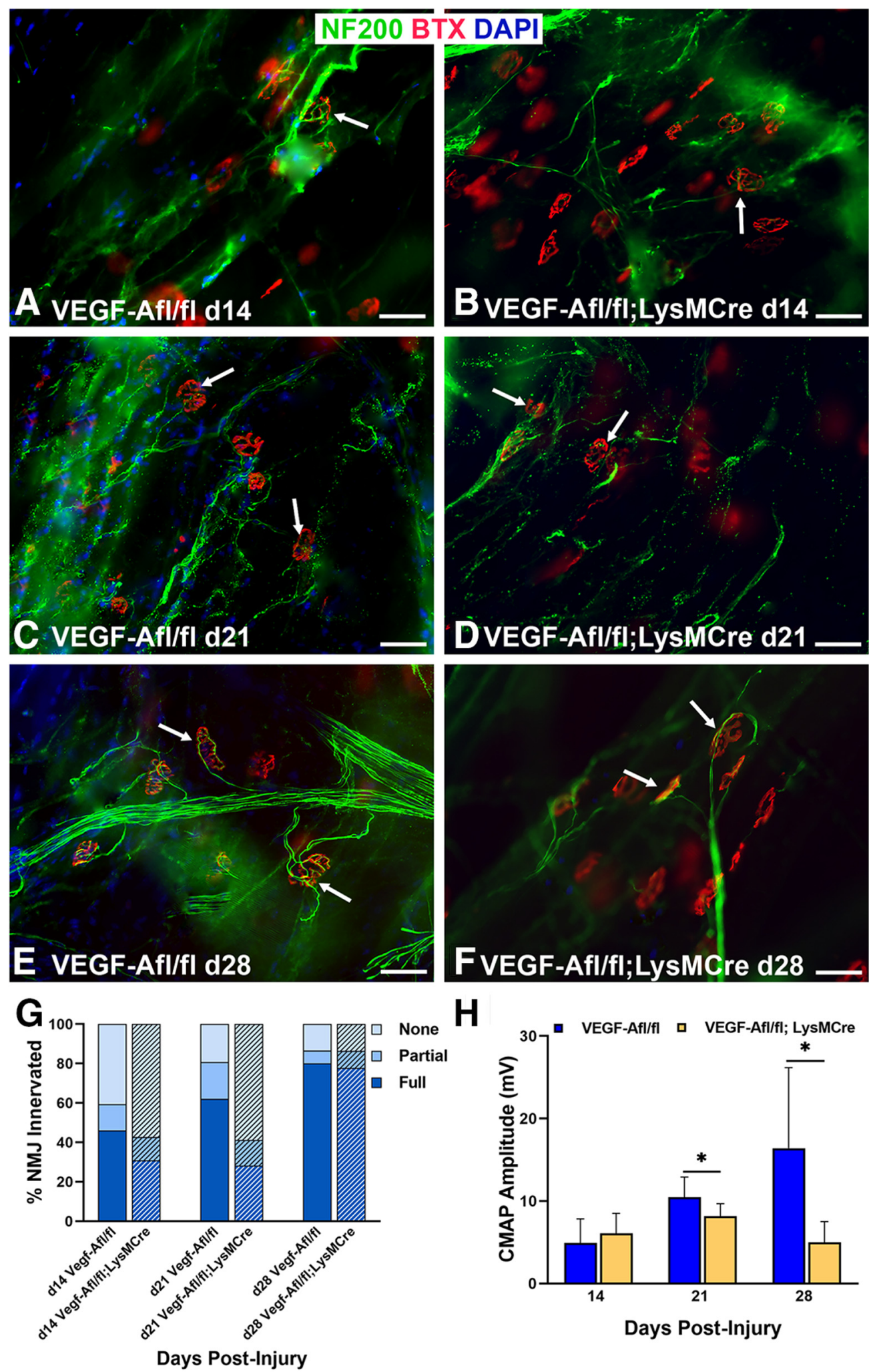

H

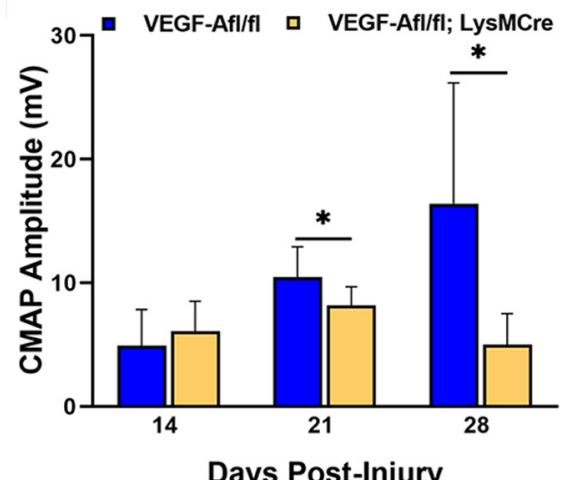

Figure 11. Innervation and functional NMJ recovery in Vegf-Af/ff; $L y s M^{(\text {re }}$ mice is persistently worse than controls. NMJ reinnervation, as seen by the colocalization of the neurofilaments (green) with motor endplates (red, arrows), is shown at days $14(\boldsymbol{A}, \boldsymbol{B}), 21(\boldsymbol{C}, \boldsymbol{D})$, and $28(\boldsymbol{E}, \boldsymbol{F})$ postinjury and nerve repair. $\boldsymbol{G}$, NMJ reinnervation was significantly worse in the Vegf-Af/f; Lys $M^{\text {(re }}$ mice, achieving only half of the reinnervation rate of controls, at day 21. Vegf- $A^{f f / f} ;$; Lys $M^{\text {(re }}$ mice showed a significantly lower percentage of fully innervated NMJs and higher percentage of denervated (none) NMJs compared with controls. By day 28 , both groups of mice were able to reach nearly $80 \%$ of motor endplates fully innervated. $\boldsymbol{H}$, Vegf-A $A^{f / f f}$; Lys $M^{\text {Cre }}$ mice demonstrated significantly poorer CMAP performance at 21 and $28 \mathrm{~d}$ postinjury compared with control mice, indicating a functional impact extending beyond morphologic differences. NF200 Ab $=$ axons (green), BTX $=\alpha$-bungarotoxin (endplates, red), DAPI $=$ nuclear staining (blue). Scale bar: $50 \mu \mathrm{m}$. Data: mean \pm SD; $N=3-5$ mice/genotype/time point; $* p<0.05$. 


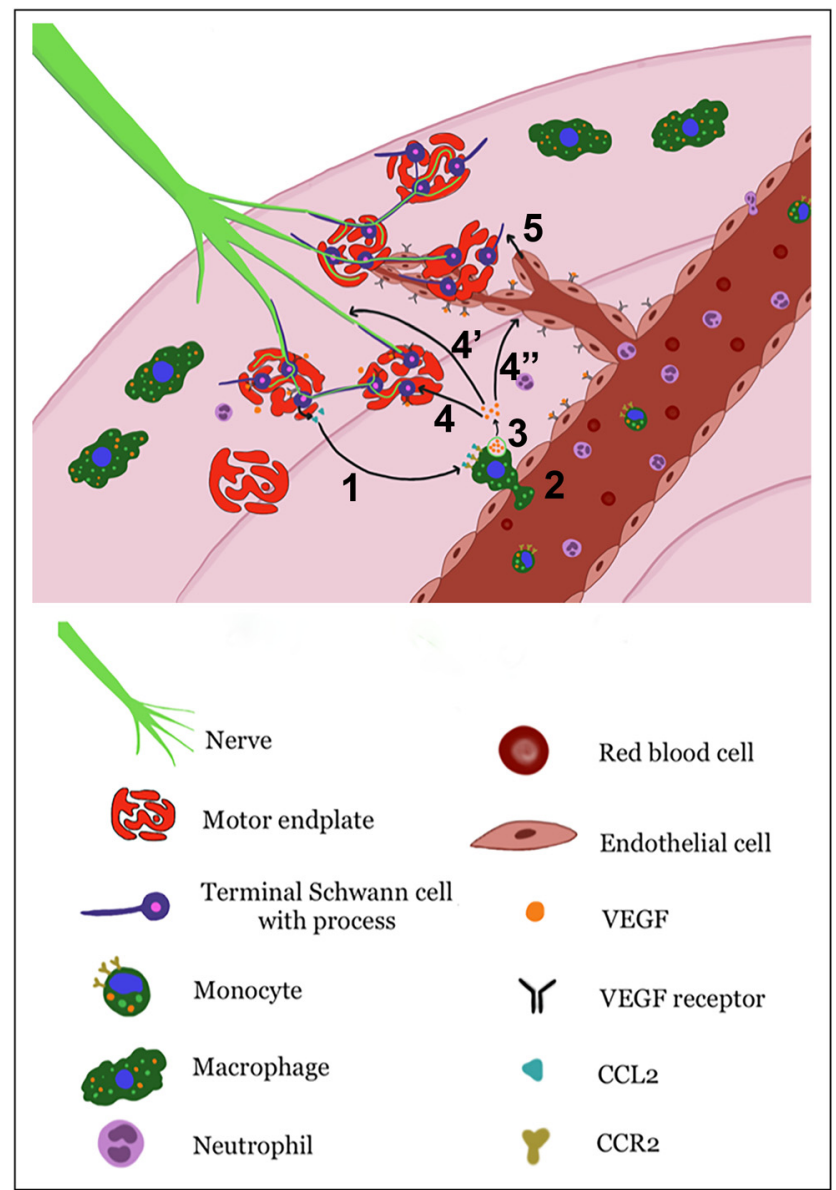

Figure 12. Illustration of proposed mechanism of Vegf-A effects on NMJ reinnervation. C $12-C \mathrm{cr} 2$ interactions (1) recruit circulating monocytes/macrophages into muscle (2) following nerve injury. Macrophages then secrete Vegf-A (3), which may have three targets: VegfRs located on $\mathrm{TSC}$, which induce $\mathrm{SC}$ process extension to guide axons to the NMJs (4), VegfRs on nerve terminals and myelinating SCs to promote axonal regeneration $\left(4^{\prime}\right)$, and VegfRs on ECs, resulting in increased vessel permeability and angiogenesis to allow delivery of additional circulating inflammatory cells to the NMJ for establishing reinnervation ( $\left.4^{\prime \prime}\right)$. Angiogenesis may then guide tSC process extensions (5) to aid NMJ reinnervation.

macrophages, whereas later they tend to differentiate into reparative phenotypes with resulting inflammation resolution (Lech and Anders, 2013; Sciorati et al., 2016; Tomlinson et al., 2018). Macrophages contribute to phagocytosis, but also facilitate healing via cytokines and growth factor secretion, yielding immune cell recruitment, angiogenesis, collagen deposition by fibroblasts, and matrix synthesis (Janis and Harrison, 2016). Finally, macrophages recruit T-lymphocytes by $5-7 \mathrm{~d}$ after injury, which contribute to healing via unclear mechanisms (Park and Barbul, 2004). Although this immune cascade was initially studied in cutaneous wound healing, an analogous process takes place after nerve transection injury.

Despite the novel findings described here, this study has important limitations. Other cells near the NMJ may compensate for altered conditions. In the circumstance of the Ccr2-/ - mice, for example, resident macrophages may compensate for absent recruited macrophages. Although macrophages are the primary Vegf-A source in muscle, ECs, for example, express Vegf-A and explain the low levels of Vegf-A expression found in the $V e g f-A^{f l / f l} ; L y s M^{C r e}$ mice. Additionally, we see a delay between NMJ morphologic changes and functional (CMAP) changes in the different experimental models. This delay likely results from poor sensitivity of CMAP testing early in reinnervation. As mice have incomplete NMJ reinnervation normally at two weeks after nerve cut and repair, differences between groups cannot be elucidated from low CMAP values. In addition, we have previously found that CMAP corresponds to complete and not partial NMJ reinnervation (Vannucci et al., 2019). Additional work is necessary to determine the signaling mechanisms at the NMJ following injury.

In conclusion, this study demonstrates multiple key findings regarding target muscle functional recovery after nerve injury. An inflammatory response occurs at the muscle, distant from the site of nerve transection. Macrophages are integral for NMJ reinnervation after injury. Vegf-A signaling is necessary for tSC process extension, timely NMJ reinnervation, and muscle function after reinnervation. Thus, macrophage-secreted Vegf-A is integral for NMJ recovery at the end target muscle after nerve injury. Our proposed mechanisms occurring at the NMJ are summarized in Figure 12. Circulating monocytes are recruited into muscle via Ccl2-Ccr2 interactions. Macrophages then secrete VegfA, which may act on tSCs, facilitating tSC process extension to induce axonal sprouting and guide axons to the NMJs. Vegf-A also induces angiogenesis, allowing delivery of additional circulating cells and guidance of tSC processes, and may also interact with nerve terminals. Additional investigation is warranted to further elucidate the details of these cellular processes at the NMJ following nerve injury.

\section{References}

Alexander KA, Chang MK, Maylin ER, Kohler T, Müller R, Wu AC, Van Rooijen N, Sweet MJ, Hume DA, Raggatt LJ, Pettit AR (2011) Osteal macrophages promote in vivo intramembranous bone healing in a mouse tibial injury model. J Bone Miner Res 26:1517-1532.

Arnold L, Henry A, Poron F, Baba-Am Y, van Rooijen N, Plonquet A, Gherardi RK, Chazaud B (2007) Inflammatory monocytes recruited after skeletal muscle injury switch into antiinflammatory macrophages to support myogenesis. J Exp Med 204:1057-1069.

Barik A, Li L, Sathyamurthy A, Xiong W-C, Mei L (2016) Schwann cells in neuromuscular junction formation and maintenance. I Neurosci 36:9770-9781.

Barrette B, Hébert M-A, Filali M, Lafortune K, Vallières N, Gowing G, Julien J-P, Lacroix S (2008) Requirement of myeloid cells for axon regeneration. J Neurosci 28:9363-9376.

Bogdanik LP, Osborne MA, Davis C, Martin WP, Austin A, Rigo F, Bennett CF, Lutz CM (2015) Systemic, postsymptomatic antisense oligonucleotide rescues motor unit maturation delay in a new mouse model for type II/III spinal muscular atrophy. Proc Natl Acad Sci USA 112:E5863E5872.

Boniakowski AE, Kimball AS, Joshi A, Schaller M, Davis FM, denDekker A, Obi AT, Moore BB, Kunkel SL, Gallagher KA (2018) Murine macrophage chemokine receptor CCR2 plays a crucial role in macrophage recruitment and regulated inflammation in wound healing. Eur J Immunol 48:1445-1455.

Boyd KU, Nimigan AS, Mackinnon SE (2011) Nerve reconstruction in the hand and upper extremity. Clin Plast Surg 38:643-660.

Burnett MG, Zager EL (2004) Pathophysiology of peripheral nerve injury: a brief review. Neurosurg Focus 16:E1.

Cattin AL, Burden JJ, Van Emmenis L, Mackenzie FE, Hoving JJA, Garcia Calavia N, Guo Y, McLaughlin M, Rosenberg LH, Quereda V, Jamecna D, Napoli I, Parrinello S, Enver T, Ruhrberg C, Lloyd AC (2015) Macrophage-induced blood vessels guide Schwann cell-mediated regeneration of peripheral nerves. Cell 162:1127-1139.

Ciaramitaro P, Mondelli M, Logullo F, Grimaldi S, Battiston B, Sard A, Scarinzi C, Migliaretti G, Faccani G, Cocito D; Italian Network for Traumatic Neuropathies (2010) Traumatic peripheral nerve injuries: epidemiological findings, neuropathic pain and quality of life in 158 patients. J Peripher Nerv Syst 15:120-127. 
Clausen BE, Burkhardt C, Reith W, Renkawitz R, Förster I (1999) Conditional gene targeting in macrophages and granulocytes using LysMcre mice. Transgenic Res 8:265-277.

Corfas G, Velardez MO, Ko C-P, Ratner N, Peles E (2004) Mechanisms and roles of axon-Schwann cell interactions. J Neurosci 24:9250-9260.

Cursiefen C, Chen L, Borges LP, Jackson D, Cao J, Radziejewski C, D’Amore PA, Dana MR, Wiegand SJ, Streilein JW (2004) VEGF-A stimulates lymphangiogenesis and hemangiogenesis in inflammatory neovascularization via macrophage recruitment. J Clin Invest 113:1040-1050.

Fantin A, Vieira JM, Gestri G, Denti L, Schwarz Q, Prykhozhij S, Peri F, Wilson SW, Ruhrberg C (2010) Tissue macrophages act as cellular chaperones for vascular anastomosis downstream of VEGF-mediated endothelial tip cell induction. Blood 116:829-840.

Faroni A, Mobasseri SA, Kingham PJ, Reid AJ (2015) Peripheral nerve regeneration: experimental strategies and future perspectives. Adv Drug Deliv Rev 82-83:160-167.

Fischer S, Weishaupt A, Troppmair J, Martini R (2008) Increase of MCP-1 (CCL2) in myelin mutant Schwann cells is mediated by MEK-ERK signaling pathway. Glia 56:836-843.

Fuchs A, Monlish DA, Ghosh S, Chang SW, Bochicchio GV, Schuettpelz LG, Turnbull IR (2019) Trauma induces emergency hematopoiesis through IL-1/MyD88-dependent production of G-CSF. J Immunol 202:30203032.

Gerber HP, Hillan KJ, Ryan AM, Kowalski J, Keller GA, Rangell L, Wright BD, Radtke F, Aguet M, Ferrara N (1999) VEGF is required for growth and survival in neonatal mice. Development 126:1149-1159.

Gomez-Sanchez JA, Pilch KS, van der Lans M, Fazal SV, Benito C, Wagstaff LJ, Mirsky R, Jessen KR (2017) After nerve injury, lineage tracing shows that myelin and Remak Schwann cells elongate extensively and branch to form repair Schwann cells, which shorten radically on remyelination. J Neurosci 37:9086-9099.

Grinsell D, Keating CP (2014) Peripheral nerve reconstruction after injury: a review of clinical and experimental therapies. Biomed Res Int 2014: 698256.

Haider MT, Hunter KD, Robinson SP, Graham TJ, Corey E, Dear TN, Hughes R, Brown NJ, Holen I (2015) Rapid modification of the bone microenvironment following short-term treatment with cabozantinib in vivo. Bone 81:581-592.

Jablonka-Shariff A, Lu CY, Campbell K, Monk KR, Snyder-Warwick AK (2019) Gpr126/Adgrg6 contributes to the terminal Schwann cell response at the neuromuscular junction following peripheral nerve injury. Glia 68:1182-1200.

Jahromi BS, Robitaille R, Charlton MP (1992) Transmitter release increases intracellular calcium in perisynaptic Schwann cells in situ. Neuron 8:1069-1077.

Janis JE, Harrison B (2016) Wound healing: part I. Basic science. Plast Reconstr Surg 138:9s-17s.

Kang H, Tian L, Thompson W (2003) Terminal Schwann cells guide the reinnervation of muscle after nerve injury. J Neurocytol 32:975-985.

Kang H, Tian L, Mikesh M, Lichtman JW, Thompson WJ (2014) Terminal Schwann cells participate in neuromuscular synapse remodeling during reinnervation following nerve injury. J Neurosci 34:6323-6333.

Ko CP, Robitaille R (2015) Perisynaptic Schwann cells at the neuromuscular synapse: adaptable, multitasking glial cells. Cold Spring Harb Perspect Biol 7:a020503.

Koh TJ, DiPietro LA (2011) Inflammation and wound healing: the role of the macrophage. Expert Rev Mol Med 13:e23.

Koirala S, Qiang H, Ko CP (2000) Reciprocal interactions between perisynaptic Schwann cells and regenerating nerve terminals at the frog neuromuscular junction. J Neurobiol 44:343-360.

Krum JM, Rosenstein JM (1998) VEGF mRNA and its receptor flt-1 are expressed in reactive astrocytes following neural grafting and tumor cell implantation in the adult CNS. Exp Neurol 154:57-65.

Kuswanto W, Burzyn D, Panduro M, Wang KK, Jang YC, Wagers AJ, Benoist C, Mathis D (2016) Poor repair of skeletal muscle in aging mice reflects a defect in local, interleukin-33-dependent accumulation of regulatory T cells. Immunity 44:355-367.

Lech M, Anders HJ (2013) Macrophages and fibrosis: how resident and infiltrating mononuclear phagocytes orchestrate all phases of tissue injury and repair. Biochim Biophys Acta 1832:989-997.

Lee YI, Li Y, Mikesh M, Smith I, Nave K-A, Schwab MH, Thompson WJ (2016) Neuregulin1 displayed on motor axons regulates terminal
Schwann cell-mediated synapse elimination at developing neuromuscular junctions. Proc Natl Acad Sci USA 113:E479-E487.

Livak KJ, Schmittgen TD (2001) Analysis of relative gene expression data using real-time quantitative PCR and the 2(-Delta Delta C(T)) Method. Methods 25:402-408.

Martin P, Leibovich SJ (2005) Inflammatory cells during wound repair: the good, the bad and the ugly. Trends Cell Biol 15:599-607.

Motoike T, Markham DW, Rossant J, Sato TN (2003) Evidence for novel fate of Flk1+ progenitor: contribution to muscle lineage. Genesis 35:153-159.

Nissen NN, Polverini PJ, Koch AE, Volin MV, Gamelli RL, DiPietro LA (1998) Vascular endothelial growth factor mediates angiogenic activity during the proliferative phase of wound healing. Am J Pathol 152:14451452.

Novak CB, Anastakis DJ, Beaton DE, Katz J (2009) Patient-reported outcome after peripheral nerve injury. J Hand Surg Am 34:281-287.

Novak CB, Anastakis DJ, Beaton DE, Mackinnon SE, Katz J (2011) Biomedical and psychosocial factors associated with disability after peripheral nerve injury. J Bone Joint Surg Am 93:929-936.

Olsson AK, Dimberg A, Kreuger J, Claesson-Welsh L (2006) VEGF receptor signalling - in control of vascular function. Nat Rev Mol Cell Biol 7:359-371.

O’Malley JP, Waran MT, Balice-Gordon RJ (1999) In vivo observations of terminal Schwann cells at normal, denervated, and reinnervated mouse neuromuscular junctions. J Neurobiol 38:270-286.

Pan D, Hunter DA, Schellhardt L, Jo S, Santosa KB, Larson EL, Fuchs AG, Snyder-Warwick AK, Mackinnon SE, Wood MD (2019) The accumulation of T cells within acellular nerve allografts is length-dependent and critical for nerve regeneration. Exp Neurol 318:216-231.

Park HW, Jeon HJ, Chang MS (2016) Vascular endothelial growth factor enhances axonal outgrowth in organotypic spinal cord slices via vascular endothelial growth factor receptor 1 and 2. Tissue Eng Regen Med 13:601-609.

Park JE, Barbul A (2004) Understanding the role of immune regulation in wound healing. Am J Surg 187:11s-16s.

Raimondo TM, Li H, Kwee BJ, Kinsley S, Budina E, Anderson EM, Doherty EJ, Talbot SG, Mooney DJ (2019) Combined delivery of VEGF and IGF1 promotes functional innervation in mice and improves muscle transplantation in rabbits. Biomaterials 216:119246.

Reddy LV, Koirala S, Sugiura Y, Herrera AA, Ko CP (2003) Glial cells maintain synaptic structure and function and promote development of the neuromuscular junction in vivo. Neuron 40:563-580.

Reist NE, Smith SJ (1992) Neurally evoked calcium transients in terminal Schwann cells at the neuromuscular junction. Proc Natl Acad Sci USA 89:7625-7629.

Reynolds ML, Woolf CJ (1992) Terminal Schwann cells elaborate extensive processes following denervation of the motor endplate. J Neurocytol 21:50-66.

Rosenstein JM, Mani N, Silverman WF, Krum JM (1998) Patterns of brain angiogenesis after vascular endothelial growth factor administration in vitro and in vivo. Proc Natl Acad Sci USA 95:7086-7091.

Rosenstein JM, Krum JM, Ruhrberg C (2010) VEGF in the nervous system. Organogenesis 6:107-114.

Santosa KB, Keane AM, Jablonka-Shariff A, Vannucci B, Snyder-Warwick AK (2018) Clinical relevance of terminal Schwann cells: an overlooked component of the neuromuscular junction. J Neurosci Res 96:1125-1135.

Schlundt C, El Khassawna T, Serra A, Dienelt A, Wendler S, Schell H, van Rooijen N, Radbruch A, Lucius R, Hartmann S, Duda GN, SchmidtBleek K (2018) Macrophages in bone fracture healing: their essential role in endochondral ossification. Bone 106:78-89.

Sciorati C, Rigamonti E, Manfredi AA, Rovere-Querini P (2016) Cell death, clearance and immunity in the skeletal muscle. Cell Death Differ 23:927937.

Shireman PK, Contreras-Shannon V, Ochoa O, Karia BP, Michalek JE, McManus LM (2007) MCP-1 deficiency causes altered inflammation with impaired skeletal muscle regeneration. J Leukoc Biol 81:775785 .

Shvartsman D, Storrie-White H, Lee K, Kearney C, Brudno Y, Ho N, Cezar C, McCann C, Anderson E, Koullias J, Tapia JC, Vandenburgh H, Lichtman JW, Mooney DJ (2014) Sustained delivery of VEGF maintains innervation and promotes reperfusion in ischemic skeletal muscles via NGF/GDNF signaling. Mol Ther 22:1243-1253. 
Sierra-Filardi E, Nieto C, Domínguez-Soto A, Barroso R, Sánchez-Mateos P, Puig-Kroger A, López-Bravo M, Joven J, Ardavín C, RodríguezFernández JL, Sánchez-Torres C, Mellado M, Corbí AL (2014) CCL2 shapes macrophage polarization by GM-CSF and M-CSF: identification of CCL2/CCR2-dependent gene expression profile. J Immunol 192:38583867.

Smith IW, Mikesh M, Lee Yi, Thompson WJ (2013) Terminal Schwann cells participate in the competition underlying neuromuscular synapse elimination. J Neurosci 33:17724-17736.

Snyder-Warwick AK, Satoh A, Santosa KB, Imai S-I, Jablonka-Shariff A (2018) Hypothalamic Sirt1 protects terminal Schwann cells and neuromuscular junctions from age-related morphological changes. Aging Cell 17:e12776.

Sobrado-Calvo P, Vidal-Sanz M, Villegas-Pérez MP (2007) Rat retinal microglial cells under normal conditions, after optic nerve section, and after optic nerve section and intravitreal injection of trophic factors or macrophage inhibitory factor. J Comp Neurol 501:866-878.

Son YJ, Thompson WJ (1995) Schwann cell processes guide regeneration of peripheral axons. Neuron 14:125-132.

Sondell M, Lundborg G, Kanje M (1999a) Vascular endothelial growth factor stimulates Schwann cell invasion and neovascularization of acellular nerve grafts. Brain Res 846:219-228.

Sondell M, Lundborg G, Kanje M (1999b) Vascular endothelial growth factor has neurotrophic activity and stimulates axonal outgrowth, enhancing cell survival and Schwann cell proliferation in the peripheral nervous system. J Neurosci 19:5731-5740.

Stockmann C, Kirmse S, Helfrich I, Weidemann A, Takeda N, Doedens A, Johnson RS (2011) A wound size-dependent effect of myeloid cellderived vascular endothelial growth factor on wound healing. J Invest Dermatol 131:797-801.
Stratton JA, Holmes A, Rosin NL, Sinha S, Vohra M, Burma NE, Trang T, Midha R, Biernaskie J (2018) Macrophages regulate Schwann cell maturation after nerve injury. Cell Rep 24:2561-2572.e6.

Tomlinson JE, Žygelyte E, Grenier JK, Edwards MG, Cheetham J (2018) Temporal changes in macrophage phenotype after peripheral nerve injury. J Neuroinflammation 15:185.

Tonari M, Kurimoto T, Horie T, Sugiyama T, Ikeda T, Oku H (2012) Blocking endothelin-B receptors rescues retinal ganglion cells from optic nerve injury through suppression of neuroinflammation. Invest Ophthalmol Vis Sci 53:3490-3500.

Vannucci B, Santosa KB, Keane AM, Jablonka-Shariff A, Lu C-Y, Yan Y, MacEwan M, Snyder-Warwick AK (2019) What is Normal? Neuromuscular junction reinnervation after nerve injury. Muscle Nerve 60:604-612.

Willenborg S, Lucas T, van Loo G, Knipper JA, Krieg T, Haase I, Brachvogel B, Hammerschmidt M, Nagy A, Ferrara N, Pasparakis M, Eming SA (2012) CCR2 recruits an inflammatory macrophage subpopulation critical for angiogenesis in tissue repair. Blood 120:613-625.

Wilson MH, Deschenes MR (2005) The neuromuscular junction: anatomical features and adaptations to various forms of increased, or decreased neuromuscular activity. Int J Neurosci 115:803-828.

Yakes FM, Chen J, Tan J, Yamaguchi K, Shi Y, Yu P, Qian F, Chu F, Bentzien F, Cancilla B, Orf J, You A, Laird AD, Engst S, Lee L, Lesch J, Chou YC, Joly AH (2011) Cabozantinib (XL184), a novel MET and VEGFR2 inhibitor, simultaneously suppresses metastasis, angiogenesis, and tumor growth. Mol Cancer Ther 10:2298-2308.

You Q, Holt M, Yin H, Li G, Hu C-J, Ju C (2013) Role of hepatic resident and infiltrating macrophages in liver repair after acute injury. Biochem Pharmacol 86:836-843. 